\title{
Autonomía local y competencias: Castilla y León en el escenario previo al pacto local
}

\author{
Ricardo Rivero Ortega
}

Universidad de Salamanca

Sumario: I. AUTONOMÍA LOCAL Y COMPETENCIA: LAS INSUFICIENCIAS DEL CONCEPTO DE «GARANTÍA INSTITUCIONAL»Y LA NECESIDAD DE REINTERPRETAR LA AUTONOMÍA EN CLAVE COMPETENCIAL. A) La interpretación positiva (pero con reservas) de la garantía constitucional de la autonomía de los municipios: las opiniones doctrinales tras la Constitución y la Ley de Bases de Régimen Local. B) Las Sentencias del Tribunal Constitucional y la evolución de la doctrina. C) La Carta Europea de la Autonomía Local. D) El Pacto Local y la necesidad de cambiar la garantía institucional por competencias, recursos y mecanismos de defensa. E) Por una reconsideración de las competencias como medida del poder local. II. LAS COMPETENCIAS MUNICIPALES EN EL DERECHO LOCAL DEL ESTADO Y EN LAS NORMAS ESTATALES REGULADORAS DE LOS DISTINTOS SECTORES DE ACTIVIDAD. A) Competencias municipales en la legislación básica estatal. Constitución y Ley de Bases de Régimen Local de 1985. B) Competencias municipales en la legislación sectorial estatal. C) El «Pacto Local» y sus consecuencias competenciales. III. LAS COMPETENCIAS DE LOS MUNICIPIOS EN LAS NORMAS DE RÉGIMEN LOCAL DE CASTILLA Y LEÓN Y EN LAS LEYES AUTONÓMICAS REGULADORAS DE LOS DISTINTOS ÁMBITOS DE ACTIVIDAD. A) El Estatuto de Autonomía de Castilla y León y los entes locales. B) La legislación de régimen local en Castilla y León. C) Las competencias de los municipios en la legislación sectorial autonómica. IV. BALANCE DE LA COMPARACIÓN DE LA NORMATIVA ESTATAL CON LA AUTONÓMICA CASTELLANO-LEONESA EN EL TRATAMIENTO DE LAS COMPETENCIAS DE LOS MUNICIPIOS. V. CONCLUSIONES: ANTE EL FUTURO PACTO LOCAL EN CASTILLA Y LEÓN.

\section{AUTONOMÍA LOCAL Y COMPETENCIA: LAS INSUFICIENCIAS DEL CONCEPTO DE «GARANTÍA INSTITUCIONAL»Y LA NECESIDAD DE REINTERPRETAR LA AUTONOMÍA EN CLAVE COMPETENCIAL}

\section{A) La interpretación positiva (pero con reservas) de la garantía constitucional de la autonomía de los municipios: las opiniones doctrinales tras la Constitución y la Ley de Bases de Régimen Local}

A estas alturas, es un lugar común aceptar que el reconocimiento de la autonomía local en la Constitución española supuso un avance político y 
administrativo respecto al anterior régimen ${ }^{1}$ : político, en la medida en que cabe entender que se trataba de profundizar en la democratización de nuestro sistema institucional, frente a su autocrático precedente; administrativo, porque puede decirse que la aproximación de la gestión de lo público a los niveles locales, en aplicación del tan reiterado principio de subsidiariedad, facilitaría una optimización de las decisiones, al menos en sus resultados para las comunidades afectadas, lo que no sucedería con el rígido centralismo. En este sentido, no se han formulado ni se formulan en estos momentos grandes críticas de fondo al enunciado de los artículos 137 y 140 de la Constitución. Al contrario, la mayor parte de los autores que los han glosado han comentado las bondades de la autonomía lo$\mathrm{cal}^{2}$.

Los estudiosos de la institución la han defendido, sin apenas crítica: resulta complicado encontrar otra decisión constitucional tan bien recibida por la doctrina, especialmente la del Derecho administrativo, pues los constitucionalistas, con alguna excepción, apenas analizaron sus implicaciones ${ }^{3}$. Otros aspectos del texto constitucional dieron lugar a polémica, y el mismo Título VIII, sobre organización territorial del Estado, ha sido tal vez uno de los bloques de más compleja interpretación, junto con los artículos de la llamada Constitución económica. El artículo 140, en cambio, seguramente por esta unánime consideración positiva de los administrativistas, no ha comenzado todavía a plantear grandes debates, aunque en los últimos tiempos sí comienza a observarse un cambio del estado de opinión en torno a la naturaleza de la autonomía municipal, profundizando en su naturaleza política, como apuntó a comienzos de los noventa SÁNCHEZ MORÓN ${ }^{4}$, y hoy sostienen otros autores ${ }^{5}$.

\footnotetext{
1 Vid. Ramón Martín Mateo/Francisco Sosa Wagner, «Cincuenta años en la Administración local», Revista de Administración Pública, n. ${ }^{\circ}$ 150, 1999.

2 Vid. Ramón Martín Mateo, «La garantía constitucional de las autonomías locales», Revista de Estudios de la Vida Local, n. ${ }^{\circ}$ 208, 1980. Antonio EmBID IRujo, «Autonomía local y Constitución: aproximación al concepto y significado de la declaración constitucional de la autonomía municipal», Revista Española de Derecho Administrativo, n. ${ }^{\circ}$ 30, 1981. Francisco Sosa WAGNER, «La autonomía municipal», Revista de Administración Pública, 100-102, 1983. Jesús Leguina Villa, «Gobierno local y Estado autonómico», Revista de Administración Pública, n. ${ }^{\circ}$ 100-102, 1983. Luis Morell Ocaña, La administración local, Tecnos, Madrid, 1984. Luciano Parejo Alfonso, «La autonomía local», Revista de Estudios de la Administración Local y Autonómica, n. ${ }^{\circ} 229$, 1986.

3 Vid. Javier García Fernández, El origen del municipio constitucional, IEAL, Madrid, 1983.

4 «... la autonomía local no es meramente autonomía administrativa, sino vehículo y forma de participación política, instancia de distribución vertical del poder, instrumento básico de democracia» Miguel Sánchez Morón, La autonomía local, Civitas, Madrid, 1990.

5 Vid. Joan Barata i Mir, Los actos de gobierno en el ámbito municipal, Tecnos, Madrid, 1999.
} 
Las opiniones doctrinales formuladas en torno a este concepto tras la Constitución y, un poco más tarde, como consecuencia de la aprobación de la Ley de Bases de Régimen Local, van sin embargo más allá del aplauso y la glosa de las ventajas del reconocimiento del autogobierno de los municipios. No incurrieron los analistas en la euforia del momento, sino que con un espíritu crítico admirable pusieron de manifiesto lo que habría que hacer para efectivamente dar cumplimiento a las declaraciones constitucionales, advirtiendo del riesgo de quedarse en la pura retórica si no se desarrollaba administrativa y, sobre todo, financieramente el espíritu de los artículos 137 y 140 de la Constitución. En este sentido, cabe decir que nuestros administrativistas de entonces - que siguen siendo los de ahora - vaticinaron muchos de los problemas, de las frustraciones y desviaciones, del inacabado desarrollo de la declaración constitucional. Los estudios sobre el tema en la década de los ochenta ilustran perfectamente la evolución posterior, anticipándose a ella muchas veces ${ }^{6}$.

Escuchemos lo que en la década de los ochenta decían los administrativistas, comenzando por Ramón MARTíN MATEO, seguramente el más destacado estudioso de nuestro régimen local, no sólo por su condición de Catedrático de Derecho Administrativo, sino también desde su experiencia de funcionario local, que en torno a la consagración constitucional de la autonomía se pronunciaba en estos términos: «En muchos casos se trata de meras declaraciones enfáticas, de carácter político y programático, cuya solemnidad no se refleja en la praxis ordinaria, al quedar constreñidos los entes locales al ejercicio de un reducido ámbito competencial, estrictamente mediatizado por las autoridades de tutela o vaciado de contenido real por la no provisión de medios financieros» ${ }^{7}$.

Debemos recordar a renglón seguido la aportación de PAREJO ALFONSO, principal introductor en nuestro país de la interpretación de la autonomía local como garantía institucional, una tesis que tendrá un rotundo éxito si la hemos de juzgar a la luz de su comentario por parte del resto de los autores en aquel momento, en el que el concepto garantía institucional se convertirá en un verdadero tópico. Y ello pese a algunas de sus consecuencias prácticas sobre los municipios, como la entrega al le-

\footnotetext{
${ }^{6}$ Muy expresivos del estado de opinión a mediados de los ochenta sobre la Administración local son los tres volúmenes publicados por el Instituto de Estudios Fiscales y la Dirección General de lo Contencioso del Estado sobre Organización Territorial del Estado (Administración Local), Madrid, 1985.

7 Ramón Martín Mateo, «La garantía constitucional de las autonomías locales», Revista de Estudios de la Administración Local y Autonómica, n. ${ }^{\circ}$ 208, 1980, p. 610.
} 
gislador de la definición del ámbito de competencias locales, advertida por el propio PAREJO: «La garantía constitucional de la autonomía local no comprende, directamente, según lo dicho, un preciso ámbito competencial, a diferencia de lo que sucede con las Comunidades Autónomas» ${ }^{8}$.

SosA WAGNER mantuvo, en cambio, una actitud pragmática y escéptica desde el principio, muy significativa si se tiene en cuenta su condición de experto localista, siguiendo la tradición de su maestro, MARTín MATEO. En tres estudios publicados consecutivamente en los números 239, 240 y 241 de la Revista de Estudios de la Administración Local y Autonómica se pronunciaba sobre el concepto, avanzando la línea a seguir si de verdad se deseaba realizar la autonomía municipal: «si la gestión de los asuntos se encomienda a personas que han obtenido su mandato como consecuencia de elecciones que protagonizan los partidos o agrupaciones electorales, eso se hará para alcanzar un objetivo de cierta magnitud, no por razones simplemente estéticas. Si las leyes no dejan el suficiente espacio a las corporaciones locales para que éstas puedan hacer opciones políticas (y no simplemente administrativas), es mejor modificar el modelo mismo, suprimir el carácter democrático de las corporaciones y confiar los servicios a organizaciones especializadas. Es, por ello, por lo que creo que autonomía y competencias (es decir, cuotas de poder político) son nociones perfectamente unidas. Y que, a su vez, la competencia atribuida a un ente local es el resultado de la identificación por el legislador de un interés local» ${ }^{9}$.

En su lúcido análisis terminaba diciendo SOSA WAGNER lo siguiente: «... hablar de autonomía de 8.000 municipios es licencia que sólo pueden permitirse personas de genio festivo. El acierto y éxito del sistema exige una reordenación del mapa municipal español sobre la base de las experiencias habidas en muchos países de nuestro entorno. No hay mucho que inventar» ${ }^{10}$. En aquel momento era necesario dar un toque de atención, que desgraciadamente fue desoído, sobre la clave del buen funcionamiento de la autonomía de los municipios, radicada en su capacidad de gestión, que depende, en todo caso, de un mínimo de población productiva de recursos suficientes para sustentar una administración y un poder político municipal. En gran medida ha de decirse que la situación actual

\footnotetext{
${ }^{8}$ Luciano Parejo Alfonso, «La autonomía local», Revista de Estudios de la Administración Local y Autonómica, n. $^{\circ} 229,1986$.

9 Francisco Sosa Wagner, «La autonomía local», Revista de Estudios de la Administración Local y Autonómica, n. $^{\circ} 241$, pp. 21-22.

${ }^{10}$ Op. cit., p. 29.
} 
de los municipios rurales y, por ende, de su autonomía es producto de no haber desarrollado soluciones como las apuntadas por SOSA WAGNER.

No era éste, por demás, un punto de vista aislado; en parecidos términos se expresaba otro experto en la materia, MORELL OCAÑA: «En efecto, y teniendo en cuenta la mínima dimensión de casi el 90 por 100 de los Municipios, y sus nulas posibilidades de sostenimiento de una organización administrativa, parece llegado el momento de afirmar que, así, la autonomía local es una utopía cada vez menos realizable, salvo para un pequeño número de Entidades locales. A las demás, el peso de la púrpura no les permite sostenerse en pie» ${ }^{11}$.

Para LEGUINA VILLA — con quien cerramos este apartado dedicado al status quaestionis en los ochenta—, la Constitución española de 1978 establece «... las bases políticas y normativas para liquidar definitivamente una concepción estato-céntrica de los asuntos públicos, rescatando a las comunidades locales de la situación de minusvalía administrativa a que hasta ahora se han visto condenadas y devolverlas al lugar que nunca debieron perder, esto es, como auténticos entes de gobierno local que han de satisfacer por igual las exigencias políticas de la comunidad vecinal y la eficaz prestación de los servicios públicos»» ${ }^{12}$. Pero advertía Leguina de las dificultades prácticas (también políticas) de la autonomía local, sobre todo en sus relaciones con las Comunidades Autónomas: «Es aquí justamente, en el terreno de la efectividad práctica del modelo autonómico, donde municipios y provincias han de encontrar los mayores obstáculos, y no sólo por la ya aludida tradición de prepotencia estatocéntrica, tan insensible y resistente al cambio operado por la norma fundamental, sino también, y muy particularmente, porque en ese obligado proceso de redistribución competencial exigido por el nuevo modelo de Estado, las corporaciones locales se enfrentan, además, con unos formidables competidores: las Comunidades Autónomas»» ${ }^{13}$.

Podríamos resumir todas estas opiniones doctrinales alcanzando algunas conclusiones: en primer lugar, se acepta gracias a la tesis de la garantía institucional que es el legislador el que desarrolla el concepto de autonomía, también en materia competencial, esto lo asumen la mayor parte de los autores; en segundo lugar, algunos autores apuntan como inconve-

\footnotetext{
11 Luis Morell Ocaña, La Administración local, Tecnos, Madrid, 1984, p. 33.

12 Jesús Leguina Villa, «Gobierno municipal y Estado autonómico», cit., p. 2189.

13 Jesús Leguina VilLA, «La autonomía de municipios y provincias en la nueva Ley básica de régimen local», Revista de Estudios de la Administración Local y Autonómica, n. ${ }^{\circ}$ 227, 1985, pp. 432-433.
} 
niente los riesgos de la pasividad del legislador en el desarrollo de una política favorecedora de la autonomía, en el terreno competencial, en el financiero o en el de la reordenación de las estructuras municipales. La función de la Ley y la incertidumbre en cuanto a lo que ésta fuera a hacer son dos claves explicativas de las opiniones doctrinales sobre la autonomía local. También serán ejes vertebradores de nuestro análisis, puesto que en este trabajo intentaremos ponderar, en el actual contexto, y en Castilla y León, si el legislador ha desarrollado o no una política de realización de la autonomía local, especialmente en lo que a la atribución de competencias a los municipios se refiere, en esta Comunidad Autónoma.

\section{B) Las Sentencias del Tribunal Constitucional y la evolución de la doctrina}

Si hubiera que citar la construcción dogmática que más ha condicionado el desarrollo de la autonomía local predicada en la Constitución, ésta sería sin duda, como ya hemos advertido en el apartado anterior, la definición de la autonomía de los municipios como «garantía institucional», una construcción de la iuspublicística germana (en su origen, de Carl SCHMITT), recibida en nuestro país por PAREJO ALFONSO ${ }^{14}$. El concepto de «garantía institucional» sirvió, en un primer momento, para explicar la posición de los municipios en la estructura institucional del Estado social y democrático de Derecho que consagraba nuestra Constitución, extendiéndose después a otros ámbitos, aunque su solidez teórica no ha dejado de ser cuestionada por algún autor, como GALLEGO ANABITARTE, desde un profundo conocimiento de la dogmática alemana ${ }^{15}$. En lo que al régimen local afecta, sin embargo, ha resuelto algunos problemas en la práctica, sobre todo en sede constitucional, planteados, por ejemplo, como consecuencia del intento de suprimir las provincias llevado a cabo por la Generalidad de Cataluña ${ }^{16}$.

Efectivamente, la consagración del concepto de «garantía institucional» como explicativo de la autonomía local se produce en la STC 32/1981, de

\footnotetext{
${ }^{14}$ Vid. Luciano Parejo Alfonso, Garantía institucional y Autonomías locales, Madrid, IEAL, 1981.

15 Vid. Alfredo Gallego Anabitarte, Derechos fundamentales y Garantías institucionales: análisis doctrinal y jurisprudencial (Derecho a la educación, autonomía local y opinión pública), Madrid, Civitas, 1994.

16 Vid. Sebastián Martín-Retortillo, «El tema de la autonomía provincial: las Diputaciones y el proceso autonómico», en La Provincia en el sistema constitucional, Diputación de Barcelona, Civitas, Madrid, 1991. Morell OcaÑa, «La provincia», en Tratado de Derecho Municipal, vol. I, Civitas, Madrid, 1988.
} 
28 de julio, en los siguientes términos: «El orden jurídico-político establecido por la Constitución asegura la existencia de determinadas instituciones, a las que se considera como componentes esenciales y cuya preservación se juzga indispensable para asegurar los principios constitucionales, estableciendo en ellas un núcleo o reducto indisponible para el legislador. Las instituciones garantizadas son elementos arquitecturales indispensables del orden constitucional y las normaciones que las protegen son, sin duda, normaciones organizativas, pero a diferencia de lo que sucede con las instituciones supremas del Estado, cuya regulación orgánica se hace en el propio texto constitucional, en éstas la configuración institucional concreta se defiere al legislador ordinario, al que no se fija más límite que el reducto indisponible o núcleo esencial de la institución que la Constitución garantiza. Por definición, en consecuencia, la garantía institucional no asegura un contenido concreto o un ámbito competencial determinado y fijado de una vez por todas, sino la preservación de la institución en términos recognoscibles para la imagen que de la misma tiene la conciencia social en cada tiempo y lugar. Dicha garantía es desconocida cuando la institución es limitada, de tal modo que se la priva prácticamente de sus posibilidades de existencia real como institución para convertirse en un simple nombre. Tales son los límites para su determinación por las normas que la regulan y por la aplicación que se haga de éstas. En definitiva, la única interdicción claramente discernible es la de la ruptura clara y neta con esa imagen comúnmente aceptada de la institución que, en cuanto formación jurídica, viene determinada en buena parte por las normas que en cada momento la regulen y la aplicación que de las mismas se hace».

Esta Sentencia fue objeto de alguna importante crítica, como la de SANTAMARÍA PASTOR, que avanzaba las ventajas, pero sobre todo los inconvenientes, de la recepción del concepto «garantía institucional» por parte del Tribunal Constitucional a la hora de definir y explicar la autonomía de Municipios y Diputaciones. El principal inconveniente, a su juicio, radicaba en la «naturaleza tendencial» del concepto, cuya realización dependería por tanto de la voluntad del legislador, que podría desconocer sus funciones, en un Estado todavía impregnado de tradición centralista. La defensa de las diputaciones que realizaba la sentencia planteaba, a su modo de ver, problemas prácticos incuestionables: «un escalonamiento múltiple de cuatro, cinco o seis niveles territoriales dotados de acervos competenciales mínimos es, desde luego, un lujo que un Estado y el bolsillo de los españoles no puede permitirse»» ${ }^{17}$.

17 Vid. Juan Alfonso SANTAMARía PASTOR, «Notas sobre la sentencia de las Diputaciones provinciales», Revista Española de Derecho Constitucional, n. ${ }^{\circ}$ 6, 1982, p. 207. 
Una de las últimas aproximaciones de importancia en la jurisprudencia del Tribunal Constitucional al significado y las implicaciones de la autonomía local se encuentra en la STC 40/1998, de 19 de febrero, que resuelve el recurso de inconstitucionalidad frente a la Ley de Puertos, haciendo referencia a sus anteriores interpretaciones del concepto de autonomía local, y en especial a sus consecuencias competenciales: «Este Tribunal ha declarado que la autonomía local prevista en los artículos 137 y $140 \mathrm{CE}$ se configura como una garantía institucional con un contenido mínimo que el legislador debe respetar y que se concreta, básicamente, en el «derecho de la comunidad local a participar a través de órganos propios en el gobierno y administración de cuantos asuntos le atañen, graduándose la intensidad de esta participación en función de la relación existente entre los intereses locales y supralocales dentro de tales asuntos o materias. Para el ejercicio de esa participación en el gobierno y administración en cuanto les atañe, los órganos representativos de la comunidad local han de estar dotados de las potestades sin las que ninguna actuación autonómica es posible...

... Este derecho de intervención en los asuntos de competencia forma, por tanto, un núcleo primigenio de la autonomía local. No obstante, este Tribunal ha señalado igualmente que la Constitución no asegura un contenido concreto o un ámbito competencial determinado y que no cabe hablar de «intereses naturales de los entes locales» (STC 32/1981)..., de manera que corresponde al legislador la determinación concreta del contenido de la autonomía local, respetando el núcleo esencial de la garantía institucional de dicha autonomía (SSTC 259/1988, 214/1989 y 46/1992) y sin romper con la «imagen comúnmente aceptada de la institución...».

En resumen, lo que se deduce de la jurisprudencia del Tribunal Constitucional es que no pueden extraerse consecuencias competenciales concretas del concepto de «garantía institucional», especialmente cuando se resuelven conflictos relacionados con materias en las que confluyen intereses locales y supralocales, esto es, autonómicos y estatales. El planeamiento urbanístico sería, en este sentido, el crisol por excelencia de intereses locales y supralocales, como demuestra una profusa jurisprudencia del Tribunal Supremo que intenta deslindar, al menos en teoría, dónde termina lo local y dónde comienza lo supralocal, lo que en un gran número de casos resulta prácticamente imposible ${ }^{18}$. Esta situación perjudica sin duda la capacidad de decisión de los municipios, en la medida en que muchas veces pueden ver seriamente limitada su autonomía por controles

18 Vid. Juan Manuel Trayter, El control del planeamiento urbanístico, Civitas, Madrid, 1996. 
ejercidos por las Comunidades Autónomas que inciden sobre asuntos que afectan directamente al círculo de sus intereses.

En cuanto al estado de opinión doctrinal en la literatura sobre el régimen local, hay que decir que evolucionó como consecuencia de esta problemática, profundizando en el estudio de las competencias municipales. En la segunda mitad de los ochenta aparecen los primeros manuales específicos sobre régimen local, como el de Francisco SOSA WAGNER ${ }^{19}$, el de Luciano Parejo Alfonso ${ }^{20}$ o el de José Luis Rivero Ysern ${ }^{21}$. Son obras construidas con los mimbres de la Ley de Bases de 1985, el Texto Refundido de disposiciones vigentes en materia de régimen local de 1986 y las primeras Sentencias del Tribunal Constitucional, sin detalladas referencias aún a la normativa autonómica, pero conscientes de la importancia de la misma para el ulterior desarrollo de la autonomía de los municipios. En estos trabajos se observa, además, una particular preocupación por la cuestión de las competencias; por ejemplo, en el último de los citados, que ponía de relieve todavía en su tercera edición la difícil defensa del espacio competencial de los municipios a la hora de valorar la construcción en nuestro sistema de la autonomía local: «... hay que relativizar esta valoración positiva si se toman en cuenta las dificultades de su aplicación práctica. Este juicio se torna especialmente crítico si se constata igualmente la ausencia de un derecho reaccional en las Entidades locales para impugnar ante el Tribunal Constitucional las disposiciones legales del Estado o la Comunidad Autónoma (leyes generales sobre Régimen local o leyes sectoriales) en las que va a concretarse y definirse, precisamente, esa autonomía local» ${ }^{22}$.

Otros estudios dignos de mención, como el de Antonio FANLO LORAS, profundizaron en este momento en los contenidos de la autonomía local, interpretada en este caso también como «título de reserva de competencias administrativas», como explica el autor: «Aunque la autonomía "no asegura un contenido concreto o un ámbito competencial determinado" (STC 28 de julio de 1981), ello no impide que pueda servir como instrumento de valoración de la acción delimitadora de las competencias locales hecha por el legislador. Lo que no quiere decir que la garantía constitucional de la autonomía incluye la determinación del contenido compe-

\footnotetext{
19 Francisco Sosa Wagner, Manual de Derecho local, Tecnos, Madrid, 1987.

20 Luciano Parejo Alfonso, Derecho básico de la Administración local, Ariel, Barcelona, 1988.

21 José Luis Rivero Ysern, Manual de Derecho local, Civitas, Madrid, 1989.

22 José Luis Rivero Ysern, Manual de Derecho Local, Tercera Edición, Civitas, Madrid, 1997, p. 49 .
} 
tencial dentro de la reserva de ley, sino que es una garantía que tiene virtualidad frente al legislador mismo. La importancia de esta operación que realiza el legislador, desde el cielo de los principios (derecho de participación) al mundo de lo concreto (titularidad de ciertos servicios y actividades), se intuye fundamental para conocer el alcance y dimensión de la autonomía local. Las técnicas de determinación de las competencias locales constituyen, pues, como he de poner de manifiesto a continuación, un aspecto de capital importancia en la medida en que, según sean las utilizadas, permitirá una expresión flexible y propicia o rígida y encorsetada del autogobierno ciudadano» 23 .

Lo que venía a decirnos FANLO es que, según cómo se atribuyeran más o menos competencias a los municipios, se realizaría así también más o menos la autonomía local. De esta forma, «... la idea de competencia se convierte en la columna vertebral del principio de autonomía» ${ }^{24}$. Y, a su juicio, el sistema arbitrado por la Ley de Bases de Régimen Local para reconocer competencias a los municipios plantea algunos problemas: «... el gran problema que plantea en estos momentos la determinación de las competencias locales es la falta de especificidad observada en los diversos supuestos en los que el legislador sectorial, estatal o regional, ha regulado un ámbito material. Cuando pueden multiplicarse los espacios administrativos en varios niveles no es posible mantener una confusión generalizada en el reparto de competencias que legitime a todos simultáneamente» ${ }^{25}$.

Ha sido la lúcida perspectiva de PARADA VÁZQUEZ, sin embargo, la que nos ha puesto más claramente de manifiesto la necesidad de interpretar la garantía institucional en un sentido competencial, pues de lo contrario vaciaríamos la autonomía de contenido: «... no es clara la utilidad que puede tener este principio de la garantía institucional de la autonomía local para evitar que una o diversas leyes no atribuyan en sus respectivos sectores competenciales municipales o provinciales, pues un derecho de participación en los asuntos públicos que afecten a la colectividad no asegura, necesariamente, que ello se traduzca en competencias, pues esta participación puede realizarse mediante otros trámites que no impliquen la titularidad ni el ejercicio de competencias reales. Sin embargo, aunque no se deriven competencias formales, el principio de participación puede

\footnotetext{
${ }^{23}$ Antonio Fanlo Loras, Fundamentos constitucionales de la autonomía local, Centro de Estudios Constitucionales, Madrid, 1990, p. 288.

${ }^{24}$ Op. cit., p. 290.

${ }^{25}$ Op. cit., p. 303.
} 
servir de soporte a la idea de una exigencia de un ámbito de competencias locales, si tenemos en cuenta que esta garantía, tal como la entiende el Tribunal Constitucional, tiene por finalidad preservar el mantenimiento de una institución en términos que la hagan reconocible con el arquetipo que hemos heredado de la misma, y ello exige que municipios y provincias sean titulares de competencias formales de carácter decisorio. En definitiva, la Ley reguladora de las bases del régimen Local, aparte de regular el derecho de participación de los entes locales en la gestión de los asuntos públicos que afecten a la respectiva colectividad, ha de fijar también las auténticas competencias locales, pues sólo de este modo puede garantizar un contenido competencial a la autonomía, que es lo que exige la jurisprudencia del Tribunal Constitucional» ${ }^{26}$.

Tras la exposición de los materiales jurisprudenciales y doctrinales, producidos a finales de los ochenta y durante la década de los noventa, puede llegarse a la conclusión de que cada vez resultaba más necesaria la concreción competencial, especialmente a nivel autonómico y sectorial, de las declaraciones constitucionales de los artículos 137 y 140, en lo relativo a la autonomía municipal. De las sentencias del Tribunal Constitucional no podía extraerse en la práctica un balance muy positivo para los municipios, al menos en lo que a sus competencias se refiere. Se plantea, a nuestro juicio, por ello, la necesidad de revisar el concepto de «garantía institucional», pues tal vez no ofrezca suficiente protección de la capacidad de decisión que debe corresponder a los municipios en la gestión de sus propios intereses.

\section{C) La Carta Europea de la Autonomía Local}

La Carta Europea de la Autonomía Local, de 15 de octubre de 1985, ratificada por España el 20 de enero de 1988, constituye un documento de garantía de la autonomía municipal patrocinado por el Consejo de Europa, al que sin embargo no se han sumado todos los países que integran esta institución, aunque en los últimos tiempos se haya producido alguna incorporación significativa ${ }^{27}$. Nuestro país, en cambio, sí ha optado por sumarse a lo establecido en la Carta, condicionando en consecuencia el desarrollo del concepto de autonomía a lo allí exigido, que puede, sin embargo, no coincidir con las tendencias del régimen local y la descentrali-

\footnotetext{
${ }^{26}$ Ramón Parada VÁzquez, «Prólogo» al libro de Mir i Bago, El sistema español de competencias locales, Marcial Pons, Madrid, 1991, p. 11.

$27 \mathrm{Vid}$. Font y LLovet, «El principio de subsidiariedad y el impulso europeo de la autonomía local», en La posición institucional de la Administración local en el siglo XXI, IVAP, Oñati, 1998.
} 
zación o la centralización administrativa en el resto de los países europeos ${ }^{28}$.

Lo que en la Carta se establece, a los efectos que ahora más nos pueden interesar, es una conexión directa entre el contenido de la autonomía y las competencias, tal y como se deduce de su artículo 4, sobre el Alcance de la autonomía local: «1. Las competencias básicas de las Entidades locales vienen fijadas por la Constitución o por la ley. Sin embargo, esta disposición no impide la atribución a las Entidades locales de competencias para fines específicos, de conformidad con la ley. 2. Las Entidades locales tienen, dentro del ámbito de la ley, libertad plena para ejercer su iniciativa en toda materia que no esté excluida de su competencia o atribuida a otra autoridad. 3. El ejercicio de las competencias públicas debe, de modo general, incumbir preferentemente a las autoridades más cercanas a los ciudadanos. La atribución de una competencia a una autoridad debe tener en cuenta la amplitud o la naturaleza de la tarea o las necesidades de eficacia o economía. 4. Las competencias encomendadas a las Entidades locales deben ser normalmente plenas y completas. No pueden ser puestas en tela de juicio ni limitadas por otra autoridad central o regional más que dentro del ámbito de la ley. 5. En caso de delegación de poderes por una autoridad central o regional, las Entidades locales deben disfrutar en lo posible de la libertad de adaptar su ejercicio a las condiciones locales. 6. Las Entidades locales deben ser consultadas, en la medida de lo posible, a su debido tiempo y de forma apropiada a lo largo de los procesos de planificación y de decisión para todas las cuestiones que les afecten directamente».

Por tanto, parece que el espacio competencial es importante para la Carta Europea. Así lo ha subrayado OrTEGA Álvarez ${ }^{29}$. No en vano desde el Preámbulo se maneja el concepto «competencias efectivas» («convencidas de que la existencia de Entidades locales investidas de competencias efectivas permite una administración a la vez eficaz y próxima al ciudadano»)). Seguramente ésta sea una de las razones más poderosas para suscribir o no los contenidos de la Carta Europea, y debe ser tenida en cuenta a la hora de deducir las implicaciones que, en nuestro ordenamiento, tiene el compromiso de asumir lo establecido en el articulado de la Carta. A nuestro juicio, su tenor literal refuerza la inter-

\footnotetext{
28 Sobre alguna de estas tendencias, puede verse el libro de Luciano Vandelli, El Poder Local. Su origen en la Francia revolucionaria y su futuro en la Europa de las regiones, Ministerio para las Administraciones Públicas, Madrid, 1992.

29 Luis Ortega Álvarez, «La Carta Europea de la Autonomía Local y el ordenamiento español», Revista de Estudios de la Administración Local y Autonómica, n. ${ }^{\circ}$ 259, 1993.
} 
pretación de la autonomía de los municipios en un sentido competencial, reduciendo un poco más el margen de libertad del legislador a la hora de optar por reconocer o no competencias a los entes municipales.

\section{D) EI Pacto Local y la voluntad de los municipios de cambiar la garantía institucional por competencias, recursos y mecanismos de defensa}

La Federación Española de Municipios y Provincias, foro de encuentro de los representantes de los entes locales, reclamó en 1995 la apertura de un proceso de negociación dirigido a conseguir que el Estado y las Comunidades Autónomas reconocieran a Ayuntamientos y Diputaciones provinciales un mayor número de competencias. Este movimiento reivindicativo, consecuencia de una cierta «insatisfacción competencial», dio lugar primero a un acuerdo con el Ministerio de Administraciones Públicas, en 1996, y un poco más adelante, a la aprobación de un documento en el Consejo de Ministros de 17 de julio de 1998 bajo la rúbrica «Medidas para el desarrollo del Gobierno Local», integrador de una serie de proyectos de ley y de medidas administrativas dirigidas, como el propio documento indica, a reforzar la posición institucional de los entes locales. El principal resultado de todo este proceso se plasmó en la reforma de la Ley de Bases de Régimen Local, la Ley Orgánica de Régimen Electoral General y la Ley Orgánica del Tribunal Constitucional, entre otras leyes, operada mediante varias Leyes orgánicas y ordinarias en 1999.

Si hemos utilizado antes la expresión «insatisfacción competencial» es debido a que éste es precisamente el sentimiento que transmite el documento de «Bases para el Pacto Local», aprobado por la Comisión Ejecutiva de la Federación Española de Municipios y Provincias en su reunión del 24 de septiembre de 1996. Falta de reconocimiento de algunas competencias e insuficiencia de medios son quejas recurrentes a lo largo de este mensaje de la voz de los entes locales en España: «Desde la promulgación de la ... Ley de Bases hasta nuestros días se ha puesto de manifiesto la insuficiencia de los mecanismos arbitrados por la misma para hacer frente a las demandas ciudadanas, insuficiencia que se refiere tanto al nivel de atribución de competencias como a la capacidad financiera de las Corporaciones Locales...

... Podemos afirmar que la iniciativa de la FEMP ha provocado una opinión unánime en todos los ámbitos de la sociedad en cuanto a la necesidad de la consecución del Pacto Local como instrumento idóneo para la solución de los déficit de las Corporaciones locales antes expuestos 
(competencial y financiero) ... Lo cierto es que parece haber llegado ya el momento de proceder a un amplio acuerdo político y territorial que posibilite que los Entes Locales ocupen su lugar en el contexto organizativo, institucional y competencial, acorde con sus capacidades y en función de esa cercanía al ciudadano, origen y destino de toda mejora territorial».

Las reclamaciones competenciales concretas se centraban en este Documento sobre las siguientes materias: circulación y transportes (sanciones de tráfico, zonas de estacionamiento limitado, retirada de vehículos abandonados, transportes urbanos); consumo (arbitraje de consumo a nivel local, consejos municipales de consumo); deportes (planificación, diseño y ejecución de instalaciones deportivas, gestión de instalaciones deportivas en los centros de enseñanza, organización de la demanda deportiva escolar); educación (participación en la programación de la enseñanza y creación de centros docentes, coordinación del diseño y ejecución de las enseñanzas de adultos); empleo (planificación, diseño de especialidades y gestión de la formación ocupacional, gestión de los programas de empleo cuyo objetivo sea la adquisición de experiencia laboral para favorecer la ocupabilidad, gestión de programas de autoempleo y asesoramiento técnico para la creación de empresas); juventud; medio ambiente (licencias, inspección y sanción, convenios o conciertos de actuación, actividades molestas, insalubres, nocivas y peligrosas); mujer (gestión de equipamientos destinados a la mujer, centros de información y asesoramiento de la mujer); protección ciudadana; sanidad; servicios sociales; turismo; urbanismo. En fin, esta lista, no exhaustiva, por prolija que pudiera parecer, demuestra el alcance y extensión de las reclamaciones competenciales, que abarcaban casi todas las materias referidas en la Ley de Bases de Régimen Local.

Tantas demandas se plasmaron, una vez conclusas las negociaciones y adoptadas las reformas, en muchas menos concesiones competenciales, y ello pese a que destacados responsables del Ministerio para las Administraciones públicas reconocieran la importancia de atribuir competencias a los municipios, asociando este proceso a la entonces todavía fomentada Administración única: «el modelo de la Administración Única no se completaría si no se produjese un paralelo proceso de desconcentración de competencias de la Administración Autonómica hacia los Ayuntamientos y Diputaciones en todos aquellos servicios en que su prestación por estos entes redunda en un mejor servicio al ciudadano» ${ }^{30}$. Estas declaraciones contrastan, no obstante, con la crítica doctrinal al olvido de

30 Jaime Rodríguez-Arana, «Administración Única y Pacto Local», Revista de Estudios de la Administración Local y Autonómica, núms. 271-272, 1996. 
los entes locales en la realización del modelo de Administración única: «Al examinar el contenido de propuesta de Administración única hemos podido comprobar cómo ésta dejaba habitualmente de lado toda la problemática relativa a la proyección intracomunitaria de la cuestión; es decir, la propuesta centraba su atención principalmente en el plano de las relaciones entre el nivel estatal y los niveles autonómicos, relegando a las Corporaciones locales a un plano marginal. Esa marginación se pretendía paliar formalmente con alguna referencia incidental en los diferentes documentos a la necesidad de que las Administraciones autonómicas también descentralizaran sus servicios a favor de las entidades locales. La doctrina, como también hemos visto, ha criticado una y otra vez ese abandono al que se ha sometido al escalón local en el desarrollo hipotético de la idea de Administración única» ${ }^{31}$.

El conflicto en defensa de la autonomía local, presentado como uno de los principales éxitos del Pacto, parece una herramienta poco eficaz por las exigencias de legitimación que plantea y por la propia situación de colapso del Tribunal Constitucional. En definitiva, después de tener que superar toda una serie de obstáculos alcanzando los consensos necesarios, los municipios pueden llegar al Tribunal Constitucional cuando éste tiene serias dificultades para dictar sentencias en plazos de tiempo que las conviertan en verdaderamente eficaces. Aunque las valoraciones de la reforma de la Ley Orgánica del Tribunal Constitucional en este punto han sido de distinto signo, pensamos que, salvo en situaciones excepcionales, la realización efectiva de la autonomía de los municipios difícilmente se logrará por este medio, al menos tal y como ha sido configurado, lo que no quiere decir que el espíritu que animó la iniciativa no fuera favorable a la realización práctica de la autonomía local, precisamente ante las insuficiencias e insatisfacciones a la que había conducido la tesis de la «garantía institucional» ${ }^{32}$.

Estas insuficiencias e insatisfacciones son más graves teniendo en cuenta el nuevo centralismo que puede observarse en algunas Comunidades Autónomas, que limitan las competencias de los municipios, y no

\footnotetext{
31 Rafael JiméneZ Asensio, La «Administración única» en el Estado autonómico, Marcial Pons, Madrid, 1998, p. 97.

32 Resulta sumamente ilustrativo el volumen publicado en 1997 por el Instituto Nacional de Administración Pública bajo el título Defensa de la Autonomía Local ante el Tribunal Constitucional, que incluye colaboraciones de constitucionalistas y administrativistas, preocupados e interesados todos ellos por la articulación del conflicto. En la exposición de alguno de los autores se expresa claramente la insatisfacción por los resultados de la consideración de la autonomía local como una «garantía institucional» a efectos de protección.
} 
sólo de los más pequeños, con menor número de habitantes y menos recursos, en beneficio de la ampliación de su propia cuota de poder, olvidando que la razón constitucional de su propia autonomía se encuentra íntimamente asociada a la de los municipios, en un mismo precepto (art. $137 \mathrm{CE}$ ). En este sentido nos manifestábamos con motivo a un comentario a la Ley de Régimen Local de Castilla y León, antes de que se planteara en esta Comunidad Autónoma la posibilidad de un Pacto Local: si el diseño definitivo del Estado de las Autonomías se concreta en la implantación de nuevos modelos centralizados y fuertemente centralistas no se comprende qué logros hubiera alcanzado la lucha por la descentralización y la aproximación de las instancias administrativas a los ciudadanos. Sustituir un centro por otro no basta para realizar la filosofía de la descentralización, que pretende ir más allá, con una división horizontal del poder y un tratamiento local de los problemas que más directamente afectan a las municipalidades.

\section{E) Por una reconsideración de las competencias como medida del poder local}

En otros ordenamientos constitucionales, la atribución de competencias en espacios concretos es la marca de hasta dónde debe llegar necesariamente la autonomía local. Esta técnica de distribución del poder entre entes territoriales, traducida en la atribución de competencias concretas, plantea numerosos inconvenientes, dada la dificultad de detectar competencias locales que puedan ser consideradas exclusivas. Basta con recordar el sinnúmero de conflictos interpretativos que han suscitado los artículos 148 y 149 de la Constitución española, que respectivamente enuncian las listas de competencias que pueden ser asumidas por las Comunidades Autónomas y las exclusivas del Estado, para darse cuenta de lo erróneo que hubiera sido una formulación constitucional en estos términos de la autonomía local, así como de su inacabado carácter normativo al no preverse desde el principio en el texto constitucional la legitimación de los entes locales para interponer recursos de inconstitucionalidad en defensa de sus competencias o, en definitiva, de su autonomía ${ }^{33}$.

\footnotetext{
33 Luis Ortega Álvarez encontraba tempranamente, no obstante, fundamento para sustentar la protección de la autonomía local mediante el recurso de amparo: «La defensa del autogobierno de los entes locales cuenta, además, a mi modo de ver, con el procedimiento directo del recurso de amparo ... cuando se vulnere o se condicione la situación de libre responsabilidad política de los representantes locales en el ejercicio de sus competencias, cuando éstas no puedan ejercerse en régimen de autogobierno por la existencia de tutelas administrativas ilegítimas, puede el ciudadano acudir a la vía de amparo para defender su esfera de participación política a través de sus representantes, puesto que habría un ámbito sobre el que se le negaría su participación...», El régimen constitucional de las competencias locales, IEAL, Madrid, 1988, pp. 29-31.
} 
La legislación española ha partido, como veremos en el apartado siguiente, de la dificultad de establecer un círculo bien definido de competencias de los entes locales, por verse afectados en numerosos intereses locales otros supralocales. Por otro lado, los análisis históricos nos demuestran que la atribución de conjuntos de competencias a los entes locales en la legislación no ha traído consigo en todo caso mayores niveles de autonomía ${ }^{34}$. Y del silencio de la Constitución al respecto se han deducido distintas consecuencias, desde la inexistencia de competencias propias de los entes locales, como en un primer momento apuntó ENTRENA CUESTA ${ }^{35}$, hasta la interpretación amplia del concepto «intereses propios» del artículo 137, aplicado a las competencias locales, en el sentido indicado por Sebastián MARTíN-RETORTILLO ${ }^{36}$.

Aun así, en el esquema de la Ley de Bases de Régimen Local que analizaremos en el siguiente apartado, los servicios mínimos locales podrían considerarse el núcleo duro competencial de los municipios, irrenunciable y de obligado cumplimiento ${ }^{37}$. Pero la tendencia hacia la liberalización de algunos de los servicios prestados por los entes locales, sea en régimen de municipalización o no, diluye también este ámbito de competencias de los municipios. Si esta tendencia avanzara sin contrapeso alguno, y en sintonía con el proceso centralizador de múltiples decisiones económicas que parece propiciar el contexto de los mercados hoy en día, terminaría vaciando de competencias a los municipios, exactamente en aquellos ámbitos donde, desde siempre, han tenido mucho que decir, en lo relativo al bienestar de las comunidades, a sus mínimos niveles de vida.

El desarrollo de la legislación sectorial plantea, por demás, ciertos riesgos para la interpretación competencial de la autonomía de los municipios. Las Comunidades Autónomas, muy especialmente, en la medida

\footnotetext{
34 Vid. Francisco Sosa Wagner/Pedro de Miguel García, Las competencias de las corporaciones locales, IEAL, Madrid, 1985. Josep MIR I BAGO, El sistema español de competencias locales, Marcial Pons, Madrid, 1991.

35 «La Constitución no reserva ... un ámbito de competencias propio del Municipio», Rafael Entrena Cuesta, «Comentario al artículo 140», en Fernando Garrido Falla, Comentarios a la Constitución, Civitas, Madrid, 1980.

36 «La determinación de funciones y competencias se formula ahora de forma mucho más sutil y efectiva; también más difícil de precisar, en base al concepto de interés, de acuerdo con lo establecido en el artículo 137 de la Constitución...», Sebastián Martín-Retortillo, «La actuación de las Corporaciones locales», Revista Española de Derecho Administrativo, n. ${ }^{\circ}$ 42, 1984, p. 333.

37 Vid. Tomás Quintana LóPez, El derecho de los vecinos a la prestación y establecimiento de los servicios públicos municipales, Madrid, 1987. Francisco Sosa WAGNER, La gestión de los servicios públicos locales, Civitas, Madrid, 1999.
} 
en que legislan sobre muchas de las materias de mayor interés para los municipios pueden acudir a distintas técnicas que menoscaban la intervención municipal. Lo explicaba muy claramente PARADA VÁZQUEZ: «... hay peligro en que, a través de otras técnicas finalistas, la autonomía pueda ser quebrantada. Así puede ocurrir con las subvenciones finalistas; o mediante la coartada de la inclusión de representantes locales en órganos colegiados de colaboración; con la posibilidad del ejercicio supletorio por el Estado y las Comunidades Autónomas de competencias locales, y porque, en definitiva, aun tratándose de competencias propias, el ejercicio autónomo de la competencia puede estar subordinado a un plan de coordinación que sustrae la potestad decisoria a la entidad local» ${ }^{38}$.

En definitiva, todas estas circunstancias relativizan sobremanera las competencias de los entes locales, en la medida en que dejan al albur del legislador ordinario, y en la mayor parte de los casos del legislador autonómico, la decisión de si los municipios deben o no intervenir sobre determinadas materias y en qué grado deben hacerlo. Ello es así porque la explicación de la autonomía local como garantía institucional ha devenido insuficiente $y$, en cierto modo, tremendamente frágil, al carecer de mecanismos jurídicos de respuesta efectiva frente al vaciamiento competencial llevado a cabo por el legislador estatal y los legisladores autonómicos, difícil de contestar sin legitimación, hasta hace bien poco, para acudir al Tribunal Constitucional. Ello obliga, como ha advertido FONT I LLOVET, a replantear los análisis de régimen local, puesto que «... el citado artículo 140 de la Constitución sigue imponiendo la garantía constitucional de la autonomía municipal y de su ejercicio a través de un gobierno y una administración comunal democrático-representativos. Efectivamente, uno de los principales objetivos que debe asumir el estudio del régimen local actual es el de delimitar la existencia de un ámbito de actuación política a favor de los Ayuntamientos, cuya extensión y límites deberán ser perfilados adecuadamente. Reconocimiento del alcance o dimensión política de la autonomía municipal que ha de superar esa vieja concepción — ciertamente utilizada en alguna ocasión por el Tribunal Constitucional - de que a los Ayuntamientos les corresponde «únicamente» una autonomía administrativa de naturaleza y calidad inferior a la de las demás instancias territoriales. La garantía constitucional de un nivel de gobierno municipal obliga, pues, a los estudiosos a profundizar, como digo, en la determinación de su contenido» ${ }^{39}$.

\footnotetext{
38 Parada VÁzQuez, op. cit., p. 12.

39 Font i Llovet, «Prólogo» al libro de Joan Barata i Mir, Los actos de gobierno en el ámbito municipal, Tecnos, Madrid, 1999, pp. 14-15.
} 
Más allá del mero estudio, parecen precisas también reformas del contexto normativo, como la apuntada por MIR I BAGO, haciendo balance de la situación de las competencias locales: «... no basta el actual marco de la Ley de Bases de Régimen Local. La experiencia frustrada del Pacto Local nos lo demuestra. Este Pacto se plantea el objetivo de conseguir un reconocimiento de competencias locales que la Ley de Bases de Régimen Local no garantiza, y las reticencias autonómicas en relación con el Pacto ponen de manifiesto que este objetivo no se alcanzará por la vía del acuerdo interinstitucional». Sin reforma de la Ley de Bases de Régimen Local, concluye MIR I BAGO, no cabe la ampliación efectiva de las competencias municipales ${ }^{40}$.

\section{LAS COMPETENCIAS MUNICIPALES EN EL DERECHO LOCAL DEL ESTADO Y EN LAS NORMAS ESTATALES REGULADORAS DE LOS DISTINTOS SECTORES DE ACTIVIDAD}

\section{A) Competencias de los municipios en la legislación básica estatal. Constitución y LBRL de 1985}

Así como a la hora de repartir las competencias entre el Estado y las Comunidades Autónomas la Constitución fue minuciosa, o al menos detallada, probablemente para evitar conflictos (que sin embargo se produjeron), resulta, como hemos visto, parca cuando se trata de especificar las competencias de los entes locales. Ello pese a la importancia de la técnica utilizada en la definición de las competencias para realizar efectivamente la autonomía, que puso de relieve, antes incluso de aprobarse la Ley de Bases de Régimen Local, ENTRENA CUESTA, comentando el que después sería artículo 2 de la Ley, que consideraba una «Manifestación ... llena de buenos propósitos, pero carente de relevancia jurídica. Puesto que, como sabemos, el precepto reproducido no podrá vincular al legislador estatal ni autonómico competente para legislar en los sectores a que se refiere. $Y$ que, además, no precisa — ni podía hacerlo- el tipo de competencia que habrá de atribuirse a los entes locales. Se trata, en definitiva, de llamar la atención sobre la necesidad de que aquéllos reconozcan ... a dichos entes algún tipo de participación en las materias que regulen» ${ }^{41}$.

\footnotetext{
40 MiR I BAGO, «Las competencias de los entes locales», en La posición institucional de la Administración local en el siglo XXI, IVAP, Oñati, 1998, pp. 264-265.

${ }^{41}$ Rafael Entrena Cuesta, «Las competencias de las entidades locales», en Organización territorial del Estado (Administración local), vol. I, IEF-DGCE, Madrid, 1985.
} 
La crítica de ENTRENA CUESTA a la técnica elegida para determinar las competencias locales en el proyecto de legislación básica estatal puede ser hoy resaltada por su visión premonitoria de los resultados que traería, al menos en lo relativo a las decisiones del legislador autonómico. Así podemos constatar, al menos en gran parte, dos de las advertencias entonces formuladas: la primera («las competencias propias... aparecen deficientemente delimitadas, en particular, en cuanto al municipio, por lo que habrá que estar, una vez más, a la legislación estatal o autonómica» ${ }^{42}$ ); la segunda ( Se consagra el derecho de los municipios y provincias a intervenir en cuantos asuntos les afecten directamente. Intervención que no habrá de traducirse necesariamente en la atribución de una competencia propia y que, además, podrá ser desconocida por las normas con rango de ley» $\left.{ }^{43}\right)$.

La Ley de Bases de Régimen Local fue, no obstante, inspirada por un espíritu de realización de la autonomía local, y puede decirse que prestó mucha atención al tema de las competencias de los municipios, siendo perfectamente consciente de su importancia. Merece la pena recordar algunos párrafos expresamente referidos a esta cuestión, en la Exposición de Motivos de la Ley: «... el régimen local, para cumplir su función de garantía de la autonomía, e incluso su cometido específico en cuanto norma institucional de la Administración local, precisa extravasar lo puramente organizativo y de funcionamiento para penetrar en el campo de las competencias...

... en punto al aspecto, absolutamente crucial, de las competencias ${ }^{44}$, la base de partida no puede ser hoy otra que la de la radical obsolescencia, por las razones ya dichas anteriormente, de la vinculación de la autonomía a un bloque de competencias por naturaleza sedicentemente locales.

En efecto, salvo algunas excepciones, son raras las materias que en su integridad puedan atribuirse al exclusivo interés de las Corporaciones locales: lógicamente también son raras aquellas en las que no exista interés local en juego...».

Ante esta dificultad de deslindar claramente cuáles serán las competencias de los entes locales, la Exposición de Motivos propone tener en cuenta tanto la autonomía local como la distribución de competencias en-

\footnotetext{
42 Op. cit., p. 110.

43 Op. cit., p. 111.

44 La cursiva es nuestra.
} 
tre el Estado y las Comunidades Autónomas y la necesidad de recurrir a la legislación reguladora de los distintos sectores de actividad. Se anticipa así la fórmula que después recogerá el artículo 2 de la Ley de Bases de Régimen Local. El papel de la legislación estatal en este diseño es marcar el «mínimo común denominador» — tal es el concepto de bases- expresado tanto en la Ley de Bases de Régimen Local como en la legislación sectorial de su competencia. Claro está que existen notables diferencias entre establecer un mínimo común denominador y enunciar una aspiración programática, y de que la legislación básica haya operado en uno u otro sentido depende, nada más y nada menos, que el grado de desarrollo de la autonomía de los municipios, más o menos intenso dependiendo de los poderes normativos del legislador autonómico y de su política en lo relativo al régimen local.

En buena medida, el reconocimiento legal de la autonomía local depende de cómo se interprete una de sus claves de bóveda, que es precisamente la declaración del artículo 2 de la Ley de Bases: «1. Para la efectividad de la autonomía garantizada constitucionalmente a las Entidades locales, la legislación del Estado y la de las Comunidades Autónomas, reguladora de los distintos sectores de acción pública, según la distribución constitucional de competencias, deberá asegurar a los Municipios, las Provincias y las Islas su derecho a intervenir en cuantos asuntos afecten directamente al círculo de sus intereses, atribuyéndoles las competencias que proceda en atención a las características de la actividad pública de que se trate y a la capacidad de gestión de la Entidad local, de conformidad con los principios de máxima proximidad de la gestión administrativa a los ciudadanos. 2. Las leyes básicas del Estado previstas constitucionalmente deberán determinar las competencias que ellas mismas atribuyan o que, en todo caso, deban corresponder a los Entes locales en las materias que regulen».

Más concreto que este mandato al legislador posterior resulta el capítulo III del Título II de la Ley 7/1985, de 2 de abril, de Bases del Régimen Local, dedicado a las competencias municipales. Este capítulo comienza con el artículo 25, que, tras formular una cláusula general habilitadora de la iniciativa municipal en su apartado primero ( $\mathrm{El}$ Municipio, para la gestión de sus intereses, y en el ámbito de sus competencias, puede promover toda clase de actividades y prestar cuantos servicios contribuyan a satisfacer las necesidades y aspiraciones de la comunidad vecinal»), recoge a continuación una lista de materias sobre las que el Municipio, en todo caso, se dice, ejercerá competencias, en los términos de la legislación del Estado y de las Comunidades Autónomas. Estas materias son: 
seguridad en lugares públicos; ordenación del tráfico de vehículos y personas en las vías urbanas; protección civil, prevención y extinción de incendios; ordenación, gestión, ejecución y disciplina urbanística; promoción y gestión de viviendas; parques y jardines, pavimentación de vías públicas urbanas y conservación de caminos y vías rurales; patrimonio histórico-artístico; protección del medio ambiente; abastos, mataderos, ferias y mercados y protección de los consumidores; protección de la salubridad pública; participación en la gestión de la atención primaria de la salud; cementerios y servicios funerarios; prestación de los servicios sociales y de promoción y reinserción social; suministro de agua y alumbrado público; servicios de limpieza viaria, de recogida y tratamiento de residuos, alcantarillado y tratamiento de aguas residuales; transporte público de viajeros; actividades o instalaciones culturales y deportivas, ocupación del tiempo libre y turismo; participación en la programación de la enseñanza y cooperación con la Administración educativa en la creación, construcción y sostenimiento de los centros docentes públicos, con intervención en sus órganos de gestión y participación en la vigilancia del cumplimiento de la escolaridad obligatoria ${ }^{45}$.

Para terminar, el apartado tercero de este precepto establece una reserva de ley que debe proteger la esfera de competencias municipales: «Sólo la Ley determina las competencias municipales en las materias enunciadas en este artículo, de conformidad con los principios establecidos en el artículo 2». Esta garantía, desde luego, resulta mucho más formal y de consecuencias jurídicas más claras que el mandato del artículo 2 de la Ley de Bases, como tempranamente advirtió ENTRENA CUESTA: «Se introduce la importante innovación de reservar a la ley la alteración del carácter de las competencias que el Proyecto enumera como propias» ${ }^{46}$. Tal reserva de ley, por otra parte, se derivaría de la consideración, anterior a la Ley de Bases, como hemos visto, de la autonomía local como «garantía institucional», lo que rotundamente reconoce José Luis RIVERO YSERN («La garantía institucional de la autonomía local comprende este primer efecto: la consagración de una reserva de ley para la determinación de las competencias locales») ${ }^{47}$.

Hay que subrayar que el listado de materias del artículo 25 no agota la regulación del tema competencial en la Ley de Bases de Régimen Local,

\footnotetext{
45 Vid. Francisco Sosa Wagner, Manual de Derecho local, cuarta edición, Aranzadi, Pamplona, 1999.

46 Rafael Entrena Cuesta, «Las competencias de los entes locales», cit., p. 110.

47 José Luis Rivero Ysern, Manual de Derecho local, cit., p. 48.
} 
pues a continuación se establece el deber de los municipios de prestar en todo caso, por sí o asociados, una serie de servicios, en orden creciente según el número de habitantes de cada municipio. Prácticamente todos estos servicios mínimos obligatorios coinciden con materias enunciadas en el artículo 25 , por lo que se entiende que se efectúa así una atribución competencial explícita, básica y por tanto general, que determina la competencia de ejecución prestacional sobre las materias mencionadas. De este modo, cuando el artículo 26.1, en su apartado a), establece que todos los municipios deberán prestar el servicio de alumbrado público, cementerio, recogida de residuos, limpieza viaria, abastecimiento domiciliario de agua potable, alcantarillado, acceso a los núcleos de población, pavimentación de vías públicas y control de alimentos y bebidas, esto quiere decir que la competencia municipal sobre las materias mencionadas se traduce en la obligación de llevar a cabo tales actividades, debiendo ser los municipios, y sólo ellos (por sí o asociados), y eventualmente apoyados por la Diputación provincial (o la Comunidad Autónoma), los que ejecuten los servicios, se entiende que a través de cualquiera de los medios previstos en la misma legislación básica de régimen local ${ }^{48}$.

Ahora bien, de ser acertada esta interpretación, en el sentido de que el artículo 26 de la Ley 7/1985 atribuye directamente competencias, no disponibles por el legislador autonómico, sino a lo sumo por el legislador estatal, que debería reformar la legislación básica para corregirlas, habría que llegar a la conclusión de que todos los Municipios, en todas las Comunidades Autónomas, deben ejercer, por ejemplo, la competencia de control de alimentos y bebidas, lo que difícilmente pueden hacer aquellos Municipios con menos recursos. Habrá que ver si la normativa estatal o autonómica en materia de inspecciones alimentarias reconoce esta competencia a los Municipios o no, y, sobre todo, si muchos de ellos están en condiciones de desarrollarla.

Por otro lado, no hay que perder de vista la posible existencia de competencias delegadas, en los términos del artículo 27 de la Ley de Bases de Régimen Local: «1. La Administración del Estado, de las Comunidades Autónomas y otras Entidades locales podrán delegar en los Municipios el ejercicio de competencias en materias que afecten a sus intereses propios, siempre que con ello se mejore la eficacia de la gestión pública y se alcance una mayor participación ciudadana. La disposición del acuerdo de delegación debe determinar el alcance, contenido,

48 «Además de las competencias stricto sensu, la Ley de Bases de Régimen Local impone a los municipios la obligación de prestar algunos servicios», Francisco Sosa WAGNer, Manual de Derecho local, cit., p. 96. 
condiciones y duración de ésta, así como el control que se reserve la Administración delegante y los medios personales, materiales y económicos que ésta transfiera. 2. En todo caso, la Administración delegante podrá, para dirigir y controlar el ejercicio de los servicios delegados, emanar instrucciones técnicas de carácter general y recabar, en cualquier momento, información sobre la gestión municipal, así como enviar comisionados y formular los requerimientos pertinentes para la subsanación de las deficiencias observadas. En caso de incumplimiento de las directrices, denegación de las informaciones solicitadas o inobservancia de los requerimientos formulados, la Administración delegante podrá revocar la delegación o ejecutar por sí misma la competencia delegada en sustitución del Municipio. Los actos de éste podrán ser recurridos ante los órganos competentes de la Administración delegante. 3. La efectividad de la delegación requerirá su aceptación por el Municipio interesado, y, en su caso, la previa consulta e informe de la Comunidad Autónoma, salvo que por Ley se imponga obligatoriamente, en cuyo caso habrá de ir acompañada necesariamente de la dotación o el incremento de medios económicos para desempeñarlos» ${ }^{49}$.

\section{B) Competencias municipales en la legislación sectorial estatal}

Las previsiones del artículo 25 de la Ley de Bases de Régimen Local necesariamente deben ser desarrolladas por las leyes reguladoras de los distintos sectores de acción pública, de acuerdo con la distribución de competencias legislativas entre el Estado y las Comunidades Autónomas que se deriva de los artículos 148 y 149 de la Constitución española. Así, no encontramos la atribución efectiva de competencias concretas a los entes locales hasta que nos aproximamos a la parte especial del Derecho administrativo, integrada por leyes que suelen dedicar algún título o capítulo al reparto de responsabilidades entre los distintos entes públicos, refiriéndose también aquí a la Administración local. Esto, sobre todo, tratándose de leyes del Estado, que han llevado a cabo una distribución de funciones entre Administración estatal, Comunidades Autónomas y entes locales, mientras que no siempre las leyes autonómicas realizan la tarea de asignar sus ámbitos competenciales a sus propios servicios y a los $\mathrm{Mu}-$ nicipios y Diputaciones provinciales.

La primera materia del apartado segundo del artículo 25 de la Ley de Bases es «Seguridad en lugares públicos». Las leyes a tener en cuenta en un análisis de su normativa aplicable son, fundamentalmente, la Ley

49 En torno a este precepto, vid. Sosa WAGNer, Manual de Derecho local, cit., pp. 63-67. 
Orgánica 2/1986, de 13 de marzo, de Cuerpos y Fuerzas de Seguridad del Estado, y la Ley Orgánica 1/1992, de 21 de febrero, de seguridad ciudadana. En ambas se dedican algunos artículos a la policía local, traducida en competencias concretas como las referidas en el artículo 53 (proteger a las autoridades de las corporaciones y sus edificios e instalaciones; ordenar, señalar y dirigir el tráfico en el casco urbano; instruir atestados por accidente de circulación dentro del casco urbano; policía administrativa; prestación de auxilio en casos de catástrofe; efectuar diligencias de prevención; vigilar los espacios públicos; cooperar en la resolución de los conflictos privados). El artículo 2 de la Ley Orgánica de Seguridad Ciudadana enuncia las autoridades competentes en materia de seguridad y no se olvida de las locales: «Sin perjuicio de lo dispuesto en el apartado anterior, las autoridades locales seguirán ejerciendo las facultades que les corresponden, de acuerdo con la Ley Orgánica de Fuerzas y Cuerpos de Seguridad y la legislación de Régimen Local, Espectáculos Públicos y Actividades Recreativas, así como de Actividades Molestas, Insalubres, Nocivas y Peligrosas» (apartado segundo).

En segundo lugar, el artículo 25.2 de la Ley de Bases de Régimen Local enuncia la materia «Ordenación del tráfico de vehículos y personas en las vías urbanas». El tráfico y circulación de vehículos a motor es una competencia exclusiva del Estado, de acuerdo con lo establecido en el artículo 149.1.21 de la Constitución española, sin perjuicio de que algunas otras materias, como las carreteras o el transporte, pueden determinar entrecruzamientos competenciales en materia de tráfico. En cualquier caso, para detectar las competencias concretas de los municipios en esta materia hemos de dirigirnos al Texto Articulado de la Ley de Tráfico, Circulación de Vehículos a Motor y Seguridad Vial, especialmente a su artícu1o 7. En tercer lugar, el apartado del artículo 25.2 de la Ley de Bases de Régimen Local enuncia la materia «Protección civil, prevención y extinción de incendios». En lo que a la protección civil se refiere, hay que tener en cuenta la Ley 2/1985, de 21 de enero, que atribuye competencias a los Municipios en sus artículos 10, 14 y 19, por ejemplo, en la aprobación de planes municipales, en la realización de pruebas de simulacro y prevención; en la promoción de la autoprotección ciudadana; o la potestad sancionadora hasta un millón de pesetas.

A continuación, en el apartado d) se recogen algunas de las materias de mayor importancia para los municipios, dada su trascendencia sobre el medio ambiente urbano y, en general, sobre el modelo de núcleo poblacional. No cabe duda de que cualquier municipio tiene un interés especialísimo en todo lo que afecte a la «Ordenación, gestión, ejecución y disci- 
plina urbanística; promoción y gestión de viviendas, parques y jardines, pavimentación de vías públicas urbanas y conservación de caminos y vías rurales». Ahora bien, la legislación urbanística ha dejado de ser, como consecuencia de la STC 61/1997, de 20 de marzo, el Real Decreto Legislativo 1/1992, de 26 de junio (Texto Refundido de la Ley del Suelo), pasando a ser integrada fundamentalmente por leyes autonómicas, con la excepción de alguna norma dirigida a realizar las competencias estatales sobre el régimen de la propiedad del suelo, o la protección del medio ambiente (Ley 6/1998, de 13 de abril, de Régimen del Suelo y Valoraciones). En consecuencia, las competencias concretas de los municipios en materia urbanística habrá que buscarlas en la legislación autonómica. No sucede lo mismo, sin embargo, con las vías urbanas, contempladas en los artículos 36 y siguientes de la Ley 25/1998, de Carreteras, estableciendo el artículo 39 la competencia de los Ayuntamientos sobre las autorizaciones para realizar obras o actividades en la zona de domino público de los tramos urbanos, autorizaciones de usos y obras en las zonas de servidumbre y afección de estos tramos de carretera, y autorizaciones sobre los terrenos y edificaciones colindantes o situadas en las zonas de servidumbre o afección en las travesías de carreteras estatales.

La siguiente materia resulta también de notable interés para muchos entes locales, por sus conexiones evidentes con la anterior, en la medida que la protección del Patrimonio histórico-artístico repercute sobre el medio ambiente urbano. En el Derecho estatal, es preciso recordar la Ley 16/1985, de 25 de junio, del Patrimonio Histórico Español, que atribuye un importante papel a los municipios en este sector de acción administrativa. El artículo 7 de esta Ley establece que «Los Ayuntamientos cooperarán con los Organismos competentes para la ejecución de esta Ley en la conservación y custodia del Patrimonio Histórico Español comprendido en su término municipal, adoptando las medidas oportunas para evitar su deterioro, pérdida o destrucción. Notificarán a la Administración competente cualquier amenaza, daño o perturbación de su función social que tales bienes sufran, así como las dificultades y necesidades que tengan para el cuidado de estos bienes. Ejercerán asimismo las demás funciones que tengan expresamente atribuidas en virtud de esta Ley». Entre estas funciones destaca la prevista en el artículo 20 de la misma Ley, en el sentido de que el Municipio o los municipios donde se declare un Conjunto Histórico, Sitio Histórico o Zona Arqueológica redacte un Plan Especial de Protección del área afectada. A partir de la aprobación de este Plan, se atribuye también a los municipios la competencia para autorizar las obras que desarrollen el planeamiento aprobado y que afecten únicamente a inmuebles que no sean Monumentos o Jardines Históri- 
cos ni estén comprendidos en su entorno, debiendo dar cuenta a la Administración competente de las autorizaciones concedidas o licencias en el plazo de diez días desde su otorgamiento (apartado cuarto del art. 20).

Mucho interés tiene también la materia mencionada en el apartado f) del artículo 25, «Protección del medio ambiente», por su alcance y sus reflejos en numerosas leyes especiales, reguladoras de cuestiones tales como el medio ambiente atmosférico (Ley 38/1972, de 22 de diciembre), en las que el papel que deben desarrollar los entes locales no es trivial, de acuerdo con el principio de «actuación local», propio del Derecho ambiental. Sus competencias sobre actividades molestas, nocivas, insalubres y peligrosas guardan una relación estrecha con la protección del medio ambiente, y otras funciones, como las relativas a la recogida de residuos, hoy regulada por Ley 10/1998, de residuos urbanos, demuestran el papel que debe corresponder a los entes locales en esta materia. El artículo 4 de la Ley de residuos, dedicado a competencias, establece en su apartado tercero lo siguiente: «Las Entidades locales serán competentes para la gestión de residuos urbanos, en los términos establecidos en esta Ley y en los que, en su caso, dicten las Comunidades Autónomas. Corresponde a los municipios, como servicio obligatorio, la recogida, el transporte y, al menos, la eliminación de los residuos urbanos, en la forma en que establezcan las respectivas ordenanzas». Los municipios pueden aprobar sus propios planes de residuos urbanos (art. 5), asumen la responsabilidad por daños desde la recepción de los residuos (art. 20) y, en el caso de los de más de 5.000 habitantes, están obligados a implantar sistemas de recogida selectiva de residuos urbanos que posibiliten su reciclado y otras formas de valorización (art. 20.3).

El apartado g) del 25.2 de la Ley se refiere a los abastos, mataderos, ferias, mercados, y a la defensa de consumidores y usuarios. Al respecto debería ser tenida en cuenta la Ley 26/1984, aunque, como veremos más adelante, Castilla y León dispone, como la mayoría de las Comunidades Autónomas, de su propia Ley de defensa de los consumidores, que atribuye competencias a los municipios. En la legislación sectorial estatal, no obstante, debe citarse la Ley de ordenación del comercio minorista, Ley $7 / 1996$, que atribuye a los municipios la competencia para autorizar y regular la venta ambulante. También se han aprobado leyes de comercio de las Comunidades Autónomas, que, por un lado, conceden competencias a los municipios, pero, por otro, abundan en la sustracción de competencias tan importantes como la relativa a la autorización de grandes superficies comerciales, atribuida hoy a las Comunidades Autónomas 
en virtud de la legislación sectorial estatal y de las propias leyes autonómicas.

El apartado h) se refiere a la competencia sobre «Protección de la salubridad pública», regulada con carácter general en la Ley 14/1986, General de Sanidad, cuyo artículo 50 reconoce la existencia de centros de salud municipales. Estrecha relación con la competencia anterior guarda la del apartado i), sobre «Participación en la gestión de la atención primaria de la salud», para la que debe ser tenida en cuenta también la Ley 14/1986, de Sanidad. Es el artículo 42 de esta norma el que establece las competencias de las corporaciones locales, en su apartado tercero: «... los Ayuntamientos, sin perjuicio de las competencias de las demás Administraciones públicas, tendrán las siguientes responsabilidades mínimas en relación al obligado cumplimiento de las normas y planes sanitarios: a) control sanitario del medio ambiente, contaminación atmosférica, abastecimiento de aguas, saneamiento de aguas residuales, residuos urbanos e industriales; b) control sanitario de industrias, actividades y servicios, transporte, ruido y vibraciones; c) control sanitario de edificios y lugares de vivencia y convivencia humana, especialmente de los centros de alimentación, peluquerías, saunas y centros de higiene personal, hoteles y centros residenciales, escuelas, campamentos turísticos y áreas de actividad físico-deportiva y de recreo; d) control alimentario de la distribución y suministro de alimentos, bebidas y demás productos directa o indirectamente relacionados con el uso y consumo humanos, así como los medios de su transporte; e) control sanitario de los cementerios y policía sanitaria mortuoria».

En el apartado k) se menciona la «Prestación de servicios sociales y de promoción y reinserción social». En este campo concreto no existe una regulación exhaustiva, más allá de las disposiciones organizativas en los distintos niveles y la regulación de las prestaciones asistenciales. Sucede algo parecido a lo que ocurre con las competencias del apartado 1), sobre «Suministro de agua y alumbrado público; servicio de limpieza viaria, de recogida y tratamiento de residuos, alcantarillado y tratamiento de aguas residuales», que tienen en común su carácter prestacional, aunque en el caso de estos servicios debe tenerse en cuenta su carácter de mínimos obligatorios en su mayor parte. También la competencia del apartado 11), dedicado al «Transporte público de viajeros», constituye un servicio mínimo obligatorio, si bien para los municipios de más de 50.000 habitantes. En la legislación sectorial estatal, en lo relativo a esta última competencia, debe recordarse la Ley 16/1987, de Ordenación de los Transportes Terrestres, seriamente afectada, como la legislación urbanística estatal, 
por la jurisprudencia del Tribunal Constitucional en torno a la cláusula de supletoriedad.

El apartado $\mathrm{m}$ ) alude a una serie de materias que guardan alguna relación, que puede resumirse en el concepto de ocio. Así, se refiere a las «Actividades o instalaciones culturales y deportivas; ocupación del tiempo libre; turismo». Podrían mencionarse aquí leyes sectoriales estatales, como la Ley 10/1990, del Deporte, que apenas atribuye competencias a los entes locales.

Por último, el apartado $\mathrm{n}$ ), que concede a los municipios la posibilidad de «Participar en la programación de la enseñanza y cooperar con la Administración educativa en la creación, construcción y sostenimiento de los centros docentes públicos, intervenir en sus órganos de gestión y participar en la vigilancia de la escolaridad obligatoria». En base a esta competencia, y por mor de la Ley Orgánica 8/1985, Reguladora del Derecho a la Educación, los municipios pueden crear centros públicos de enseñanza. Asimismo, hay que tener en cuenta las previsiones de la Ley Orgánica 10/1990, de Ordenación General del Sistema Educativo, que contempla las competencias municipales de conservación, mantenimiento y vigilancia de los edificios dedicados a educación infantil, primaria o especial, así como la cooperación para obtener los solares necesarios para la construcción de escuelas y colegios.

\section{C) El «Pacto local» y sus consecuencias competenciales}

El 21 de abril de 1999 las Cortes Generales aprobaron un paquete de medidas dirigidas a implementar el llamado «Pacto local», producto como hemos visto anteriormente de un acuerdo entre la FEMP y el MAP, dirigido a afianzar la posición institucional de los entes locales en nuestro país ${ }^{50}$. Como es bien sabido, estas leyes son: Ley Orgánica 7/1999, de modificación de la Ley Orgánica 2/1979, de 3 de octubre, del Tribunal Constitucional; Ley Orgánica 8/1999, de modificación de la Ley Orgánica 5/1985, de 19 de junio, de régimen electoral general; Ley Orgánica 9/1999, de modificación de la Ley Orgánica 9/1983, de 3 de julio, reguladora del Derecho de Reunión; Ley Orgánica 10/1999, de modificación de la Ley 8/1985, de 3 de julio, reguladora del Derecho a la Educación; Ley Orgánica 10/1999, de modificación de la Ley Orgánica 1/1992, de 21 de febrero, sobre protección de la seguridad ciudadana; Ley Orgánica

${ }^{50}$ Vid. El Pacto local. Medidas para el desarrollo del Gobierno Local, FEMP/MAP, Madrid, 1999. 
11/1999, de modificación de la Ley 7/1985, de 2 de abril, reguladora de las bases de régimen local, y otras medidas para el desarrollo del Gobierno local en materia de tráfico, circulación de vehículos a motor y seguridad vial y en materia de aguas.

De estas leyes, varias afectan a cuestiones competenciales, ampliando las de los entes locales en varias materias. Así, se posibilita que los municipios afectados por el ejercicio del derecho de reunión sean informados y se pronuncien al respecto, se introduce la participación de las Corporaciones locales en el Consejo Escolar del Estado; se habilita a los municipios para que especifiquen en sus ordenanzas los tipos definidos en la Ley de seguridad ciudadana, y se regulan las competencias de los municipios sobre vehículos abandonados, permitiendo su retirada. De poco servirá el Pacto local, sin embargo, si el movimiento descentralizador, por la realización del principio de subsidiariedad, no se produce también a nivel autonómico. Así lo ha manifestado, cabalmente, el actual Director del INAP, a la sazón Subsecretario del Ministerio para las Administraciones Públicas ${ }^{51}$.

\section{LAS COMPETENCIAS DE LOS MUNICIPIOS EN LAS NORMAS DE RÉGIMEN LOCAL DE CASTILLA Y LEÓN Y EN LAS LEYES AUTONÓMICAS REGULADORAS DE LOS DISTINTOS SECTORES DE ACTIVIDAD}

\section{A) El Estatuto de Autonomía de Castilla y León y los entes locales}

La norma institucional básica de la Comunidad Autónoma de Castilla y León es su Estatuto, aprobado por Ley Orgánica 4/1983, de 25 de febrero, norma que ha experimentado dos reformas importantes, obradas respectivamente por la Ley Orgánica 11/1994, de 24 de marzo, y la Ley Orgánica 4/1999, de 8 de enero. Hay que resaltar que ya en el Preámbulo del Estatuto encontramos el reconocimiento de la importancia de los municipios y, en general, de los entes locales: «De acuerdo con su propia tradición histórica, los Municipios y las Diputaciones Provinciales ven expresamente declarada la autonomía que la Constitución les reconoce, al tiempo que el Estatuto establece los mecanismos adecuados que, a través de la participación de aquéllas, permitan la más amplia descentralización funcional en el ámbito de la Comunidad». Parece reconocerse, como puede observarse, mayor relevancia a las Diputaciones que a los municipios,

51 Jaime Rodríguez-Arana MuÑoz, «El fortalecimiento del poder local», Actualidad Administrati$v a$, n. $^{\circ} 3,17$ al 23 de enero de 2000. 
lo que puede encontrar justificación en las características geográficas peculiares de esta Comunidad Autónoma 52.

El Capítulo IV del Título I, sobre organización de la Comunidad, está dedicado a la organización territorial, y allí se encuentra, en el artículo 25, apartado primero, la única referencia expresa y directa al Municipio: «El Municipio es la entidad local básica de la Comunidad. Goza de personalidad jurídica propia y de plena autonomía para la gestión de sus intereses. Su representación, gobierno y administración corresponde al respectivo Ayuntamiento». Asimismo, en este precepto (apartado cuarto) se remite a una Ley de las Cortes de Castilla y León la regulación de las Entidades Locales Menores y otras formas tradicionales de organización municipal, la creación de mancomunidades y otras formas de agrupación de municipios. Se entiende que sean éstas las primordiales preocupaciones del poder público castellano-leonés en lo que al régimen local se refiere, lo que resulta fácilmente comprensible si se parte de un conocimiento apropiado de la realidad municipal en Castilla y León ${ }^{53}$.

Si las Cortes de Castilla y León pueden regular materias como las entidades locales menores, las agrupaciones de municipios o las mancomunidades, y en general aprobar normas sobre régimen local, es porque la asunción de competencias al respecto en el Estatuto ha ido más allá de lo establecido en el artículo 148.1.2 de la Constitución española («Las alteraciones de los términos municipales comprendidos en su territorio y, en general, las funciones que correspondan a la Administración del Estado sobre las Corporaciones locales y cuya transferencia autorice la legislación sobre Régimen Local»), siendo en estos momentos, tras la última reforma, competencia autonómica el Régimen Local, expresamente mencionada en el apartado tercero del artículo 34 del Estatuto de Autonomía castellano-leonés, dedicado a las competencias de desarrollo normativo y ejecución.

\section{B) La legislación de régimen local en Castilla y León}

Como principal antecedente del régimen local en Castilla y León debe citarse la Ley 6/1986, reguladora de las relaciones entre la Comunidad de Castilla y León y los entes locales. Esta norma preveía delegaciones com-

\footnotetext{
52 Vid. Enrique Rivero Ysern (coord.), Comentario al Estatuto de Autonomía de Castilla y León, IEAL, Madrid, 1985.

53 Vid. Francisco Sosa WAGNER, «Creación y supresión de municipios, y alteraciones de sus términos», en Javier García Roca (coord.), Derecho público de Castilla y León, Valladolid, 1999.
} 
petenciales en el nivel local, persiguiendo así un incremento de la descentralización ${ }^{54}$. Esta Ley reconocía desde su Exposición de Motivos la importancia del artículo 20 del Estatuto de Autonomía, en su redacción original, pero en su articulado sólo se encontraban referencias a la transferencia, la delegación, la colaboración y la coordinación. Esquivó, en cambio, el tratamiento de la gestión ordinaria de los servicios periféricos de la Comunidad por las Diputaciones provinciales, a la que se refería el apartado 2 del artículo 29 del original Estatuto de Autonomía ${ }^{55}$.

Hasta 1998, sin embargo, no se aprueba una ley de régimen local en Castilla y León, última Comunidad Autónoma en el acceso cronológico al Estatuto de Autonomía. De hecho, la competencia en materia de régimen local no se asume en el Estatuto hasta la reforma de 1999, lo que podría plantear tal vez alguna objeción por la anticipada aprobación de la Ley 1/1998, si el Tribunal Constitucional no hubiera utilizado ya alguna vez la doctrina de la «constitucionalidad sobrevenida» en materia competencial, casualmente en relación a esta misma Comunidad Autónoma, y referida a su Ley de industria. Además, lo cierto es que la Ley de régimen local no es estrictamente tal, pues no agota, ni mucho menos, las cuestiones a regular por el poder normativo autonómico, como demuestran otras leyes autonómicas sobre la misma materia, asumida igualmente en los Estatutos de Autonomía de Cataluña o Galicia, por ejemplo ${ }^{56}$.

El Título IV de esta Ley va encabezado por el rótulo «Competencias y Servicios Municipales», y se divide en dos capítulos, el primero de los cuales, específico sobre competencias, incluye un único artículo, el número 20 , que se limita a enunciar las materias sobre las que los municipios de Castilla y León ejercerán competencias, en los términos de la legislación del Estado y de la Comunidad Autónoma: seguridad en lugares públicos; ordenación del tráfico; Protección civil, prevención y extinción de incendios; ordenación, gestión, ejecución y disciplina urbanística; parques y jardines; pavimentación y conservación de vías y caminos; promoción y gestión de viviendas; patrimonio histórico-artístico; medio ambiente, gestión de montes y espacios naturales; actividades clasificadas;

\footnotetext{
${ }^{54}$ Vid. José Luis Martínez LóPez-MuÑız, «Descentralización local en Castilla y León», en Descentralización y Administración local, Valladolid, 1992.

55 Vid. Antonio CAlonge VelázquEZ, «Un exponente de la problemática actual entre Comunidades Autónomas y Provincias: la gestión ordinaria de los servicios periféricos propios de la Comunidad Autónoma a través de las Diputaciones provinciales», Revista de Estudios de la Administración Local y Autonómica, n. ${ }^{\circ} 232,1986$.

56 Vid. Ricardo Rivero Ortega, «Régimen local de Castilla y León: estudio de la Ley 1/1998, de 4 de junio», Revista de Estudios de la Administración Local y Autonómica, n. ${ }^{\circ}$ 277, 1998.
} 
defensa de consumidores y usuarios; equipamientos comerciales, abastecimientos y mataderos; salud pública y sanidad; alumbrado público; red de suministro y tratamiento del agua, servicios de limpieza viaria, de recogida y tratamiento de residuos; acción social y servicios sociales, protección de la infancia, atención a la juventud y promoción de la igualdad de la mujer, prevención de la marginación e inserción social; transporte público; cultura; deportes; turismo y tiempo libre; colaboración con la administración educativa en la creación, construcción y mantenimiento de centros docentes públicos y en la escolarización; cementerios y servicios funerarios; cualesquiera que se les atribuyan en su ámbito territorial y de gestión.

\section{C) Las competencias de los municipios en la legislación sectorial autonómica}

Así como al analizar la atribución de competencias a los entes locales hemos partido de la normativa básica de régimen local, para descender a continuación a las normas reguladoras de los distintos sectores de acción administrativa, también debemos referirnos a las leyes sectoriales aprobadas en Castilla y León si queremos conocer en concreto qué competencias se reconocen a los municipios. Sólo dispondremos de una panorámica completa de las competencias municipales una vez consultadas las leyes estatales y autonómicas, comprobando así además el grado de cumplimiento efectivo del artículo 2 de la Ley de Bases de Régimen Local, que establece una obligación pretendidamente vinculante tanto para el legislador estatal como para los legisladores autonómicos.

La primera materia a la que se refiere el artículo 20 de la Ley 1/1998, de 4 de junio, es la «Seguridad en lugares públicos». La normativa autonómica sobre esta materia trae causa de la competencia recogida en el artículo 33 de la Ley Orgánica 4/1983, de 25 de febrero, del Estatuto de Autonomía de Castilla y León, cuyo apartado tercero establece: «Corresponde a la Comunidad Autónoma la coordinación y demás facultades previstas en la Ley Orgánica a que se refiere el número 22 del artículo 148.1 de la Constitución, en relación con las policías locales de Castilla y León, sin perjuicio de su dependencia de las autoridades locales». La citada Ley Orgánica es, como ya sabemos, la de Fuerzas y Cuerpos de Seguridad (Ley Orgánica 2/1986, de 13 de marzo). De acuerdo con esta previsión se dictó la Ley 12/1990, de 28 de noviembre, de coordinación de policías locales de Castilla y León, una ley sin implicaciones competenciales, con una finalidad meramente armonizadora de las funciones y, sobre todo, el régimen jurídico del personal de las policías dependientes de 
los municipios castellano-leoneses (selección y promoción de sus miembros, formación y movilidad, medios de información, etc.). El reparto de competencias queda agotado, por tanto, en la normativa estatal, al menos en el caso de Castilla y León.

Tampoco encontramos atribuciones competenciales específicas con respecto a la segunda materia prevista en el artículo 20 de la Ley 1/1998: «Ordenación del tráfico». Hemos visto anteriormente que al tratarse de una competencia exclusiva del Estado, ex artículo 149.1.21 de la Constitución, difícilmente puede producirse una intervención normativa de la Comunidad Autónoma sobre la materia. Algo similar sucede con la competencia de protección civil, del apartado c) del artículo 20, aunque el artículo 149 de la Constitución no la mencione expresamente, pero al no haber sido asumida por el Estatuto de Autonomía de Castilla y León no se puede legislar al respecto. En cambio, la competencia sobre prevención y extinción de incendios sí ha sido regulada, en desarrollo de las previsiones del artículo 34 del Estatuto de Autonomía de Castilla y León, en sus apartados quinto («Protección del medio ambiente y de los ecosistemas...») y noveno («Montes, aprovechamientos y servicios forestales, vías pecuarias, pastos y espacios naturales protegidos»). Así, se han dictado sobre esta materia el Decreto 63/1985, de 27 de junio, sobre prevención y extinción de incendios forestales, que contempla el necesario visto bueno del Alcalde para la quema de rastrojos, la Orden de 26 de junio de 1995, de la Consejería de Medio Ambiente y Ordenación del Territorio, por la que se establecen las normas básicas de actuación en caso de incendio y las competencias y obligaciones de los técnicos en su extinción, que contempla una intervención de la Autoridad local, y la Orden de 5 de febrero de 1996, de la Consejería de Medio Ambiente y Ordenación del Territorio, por la que se regulan las autorizaciones para aprovechamientos de pastos en montes afectados por incendios forestales, que contempla el traslado de copia de las solicitudes de autorización al Ayuntamiento o Ayuntamientos en que estén ubicados los terrenos, para su constancia e información pública a los interesados.

La materia del apartado d) del artículo 20 de la Ley 1/1998 es la «Ordenación, gestión, ejecución y disciplina urbanística», una materia que, como hemos advertido en el apartado anterior, es sumamente trascendente para los municipios, por lo que aquí la atribución de competencias resulta, de todo punto, obligada. Una vez se plantea la necesidad de que las Comunidades Autónomas legislen sobre esta materia, al declararse contraria a la Constitución la supletoriedad del Derecho urbanístico dictado por el Estado, por mor de la STC 61/1997, de 20 de marzo, las 
Cortes de Castilla y León se ven obligadas a dictar una ley urbanística, la Ley 5/1999, de 8 de abril, de Urbanismo de Castilla y León. En el artículo 3 de esta Ley, bajo el título «Gestión y dirección de la actividad urbanística», se dice lo siguiente: «La dirección y el control de la actividad urbanística corresponde a la Comunidad Autónoma y a los municipios de Castilla y León, dentro de sus respectivas competencias, sin perjuicio de la participación de las restantes Administraciones públicas y de la iniciativa privada, en las formas previstas en esta ley».

Los artículos 111 y 132 de la Ley 5/1999 son particularmente relevantes para la materia que aquí tratamos. El primero, dedicado a las competencias, establece que corresponden al municipio las competencias de protección de la legalidad urbanística en su término municipal (inspección urbanística, medidas de protección y restauración de la legalidad urbanística e imposición de sanciones a las infracciones urbanísticas), pero a renglón seguido, en su segundo apartado, precisa que «cuando el Ayuntamiento no ejerza dichas competencias conforme a lo dispuesto en este capítulo, las mismas corresponderán a la Diputación provincial, que podrá ejercerlas directamente o bien aportando los medios técnicos y económicos de los que carezca el Ayuntamiento». Se contempla por tanto una subrogación en la competencia municipal, subrogación que también cabe, pero en beneficio de la Comunidad Autónoma, tratándose de la elaboración y aprobación del planeamiento (art. 59 de la Ley). Así, la competencia municipal lo es sólo y en la medida en que sea efectivamente ejercida, lo que sitúa a los pequeños municipios en una posición más frágil a la hora de asumir competencias sobre esta materia.

Íntimamente relacionada con las competencias urbanísticas se encuentran las referidas a las materias de los apartados d) y e) del artículo 20 de la Ley 1/1998. La primera, «Parques y jardines; pavimentación y conservación de vías y caminos», tratada tanto en la Ley urbanística de Castilla y León como, en lo que a la segunda materia se refiere, en la Ley 2/1990, de 16 de marzo, de Carreteras de Castilla y León, que regula en su Capítulo IV las Travesías y tramos urbanos. La materia del apartado e), «Promoción y gestión de viviendas», está también conectada a la materia urbanística.

A continuación, el apartado g) del artículo 20 enuncia otra materia que también guarda estrecha relación con la intervención urbanística, cual es el Patrimonio histórico-artístico, una materia de singularísima importancia en Castilla y León, como demuestra la redacción del Estatuto de Autonomía, cuando establece en su artículo 4, sobre valores esenciales, que «La Lengua castellana y el patrimonio histórico-artístico y natural son 
valores esenciales para la identidad de la Comunidad de Castilla y León y serán objeto de especial protección y apoyo, para lo que se fomentará la creación de entidades que atiendan a dicho fin». Medio ambiente y patrimonio histórico-artístico son, por tanto, valores esenciales de esta Comunidad, encontrándose además la primera materia entre las competencias exclusivas de la Comunidad Autónoma, de acuerdo con lo establecido en el apartado 12 del artículo 32 del Estatuto («Patrimonio histórico-artístico, monumental, arqueológico, arquitectónico y científico de interés para la Comunidad, sin perjuicio de la competencia del Estado para su defensa contra la exportación y la expoliación»). Sorprende, sin embargo, la falta de una Ley general castellano-leonesa sobre esta materia, integradora de una regulación dispersa hoy en normas como la Ley 9/1989, de 30 de noviembre, de Bibliotecas de Castilla y León, la Ley 6/1991, de Archivos y del Patrimonio Documental de Castilla y León, o la Ley 10/1994, de Museos de Castilla y León. Sorprende, en cualquier caso, la escasa o nula atención al papel de los entes locales en estas leyes que regulan aspectos capitales de la acción cultural, en una Comunidad Autónoma en la que el patrimonio ha permanecido olvidado durante décadas en pequeños pueblos, a expensas de expoliadores y desaprensivos.

Si es importante para Castilla y León la protección de su patrimonio histórico-artístico, también lo es la protección del medio ambiente, según lo establecido en el artículo 4 del Estatuto de Autonomía, antes citado. En este caso, sin embargo, encontramos la competencia autonómica en el artículo 34 del Estatuto, sobre competencias de desarrollo normativo y ejecución, cuyo apartado 5 atribuye a la Comunidad competencia sobre «Protección del medio ambiente y de los ecosistemas, sin perjuicio de las facultades de la Comunidad Autónoma para establecer normas adicionales de protección en los términos del artículo 149.1.23 de la Constitución. La legislación medioambiental en Castilla y León apenas ha reconocido competencias municipales, como puede observarse en la Ley 8/1994, de 24 de junio, de Evaluaciones de Impacto Ambiental de Castilla y León.

En cuanto a la competencia sobre actividades clasificadas, ha de tenerse en cuenta la Ley de actividades clasificadas de Castilla y León, Ley 5/1993, de actividades molestas, insalubres, nocivas y peligrosas. Esta norma reconoce en su artículo tercero la competencia del Ayuntamiento para otorgar la licencia de actividad (art. 3) y la licencia de apertura (art. 16), y adicionalmente establece que «la inspección de las actividades clasificadas corresponde al Ayuntamiento en cuyo ámbito territorial estén ubicados» (art. 20). 
El régimen de la defensa de consumidores y usuarios en esta Comunidad Autónoma ha sido abordado por la Ley 11/1999, de 5 de diciembre, de consumo en Castilla y León. Esta norma no efectúa un reparto competencial entre los distintos poderes públicos, sino que, una y otra vez, se refiere en su articulado a las Administraciones públicas de Castilla y León en el ámbito de sus respectivas competencias. Así, por ejemplo, puede citarse el artículo 9.1 de la Ley: «Las Administraciones públicas, en el ámbito de sus respectivas competencias, adoptarán las medidas necesarias destinadas a asumir los siguientes objetivos...»; o el artículo 20, que comienza con una fórmula semejante: «Las Administraciones públicas de Castilla y León con competencias en materia de consumo podrán crear servicios u oficinas públicas de información y protección al consumidor...».

Con respecto a los equipamientos comerciales, debe atenderse a la Ley 2/1996, de 18 de junio, cuyo artículo 3 establece que «De conformidad con la legislación vigente, los Ayuntamientos concederán las preceptivas licencias para la instalación de los establecimientos comerciales en los respectivos términos municipales, previa comprobación del cumplimiento de los requisitos legales, y ejercerán sus competencias en materia de regulación, inspección, ordenación y disciplina urbanística de los establecimientos comerciales». Ahora bien, esta misma Ley recuerda en su artículo 11 que la apertura de grandes superficies comerciales exige una licencia cuya concesión corresponde a la Comunidad Autónoma.

Gran parte de las competencias que completan el artículo 20 de la Ley de régimen local de Castilla y León se refieren a actividades prestacionales que responden a las actividades de servicios mínimos obligatorios (alumbrado público, red de suministro y abastecimiento de agua, transporte público, etc.) o a una intervención social que, a nivel autonómico, está sobre todo a cargo de la Gerencia de Servicios Sociales constituida por la Junta, que se ocupa de materias como la protección de la infancia, la prevención de la marginación e inserción social. Mención aparte merecería el turismo, detalladamente regulado por la Ley 10/1997, de 19 de diciembre, que dedica el capítulo III de su primer Título a las competencias de la Administración local. Sobre las competencias de los Ayuntamientos se pronuncia el artículo 9 de la Ley, atribuyéndoles entre otras la promoción de los recursos y productos turísticos existentes en su ámbito, el fomento de las actividades turísticas o la protección y conservación de sus recursos turísticos. Lo cierto es que, con independencia de la sustancia mayor o menor de estas competencias, se echa en falta en otras leyes de la Comunidad Autónoma el tratamiento específico de las competencias municipales en este ámbito. 


\section{BALANCE DE LA COMPARACIÓN DE LA NORMATIVA ESTATAL CON LA AUTONÓMICA CASTELLANO-LEONESA EN EL TRATAMIENTO DE LAS COMPETENCIAS DE LOS MUNICIPIOS}

Superponiendo lo establecido en la Ley de Bases de Régimen Local y en las leyes estatales reguladoras de los distintos sectores de actividad cuando atribuyen competencias a los entes locales, al contenido de las leyes de Castilla y León, de régimen local y reguladoras de los distintos sectores de actividad administrativa, obtenemos el resultado del desarrollo de la autonomía local, en el plano de las competencias, en esta Comunidad Autónoma. Como balance normativo, ha de ser elemento de juicio para determinar el grado de compromiso del legislador autonómico castellano-leonés con el principio constitucional de autonomía municipal, así como con el mandato de la Ley de Bases de Régimen Local, que le condiciona por su carácter básico conforme a lo establecido en el artículo 149.1.18 de la Constitución española.

En esta comparación de la normativa básica estatal de régimen local y la legislación castellano-leonesa, se hace obligado el contraste del artículo 25 de la Ley 7/1985, de 2 de abril, de Bases de Régimen Local, y el artículo 20 de la Ley 1/1998, de 4 de junio, de Régimen Local de Castilla y León, pues ambos enuncian sendas listas de materias sobre las que parece obligado reconocer competencias a los municipios. En estos listados, la gran mayoría de las materias citadas son coincidentes, así: Seguridad en lugares públicos; protección civil y prevención y extinción de incendios; urbanismo; vivienda; patrimonio; medio ambiente; defensa de consumidores y comercio; sanidad; cultura. En fin, casi todas las materias que menciona el artículo 20 de la ley castellano-leonesa se encontraban antes en la ley estatal. Algunas materias, sin embargo, podrían considerarse nuevas: actividades clasificadas; protección de la infancia, atención a la juventud y protección de la igualdad de la mujer; equipamientos comerciales, etc.

La novedad no es tal, sin embargo, teniendo en cuenta que ya el artículo 28 de la Ley de Bases de Régimen Local abría la posibilidad de actividades complementarias de los municipios respecto de las desarrolladas por otras Administraciones públicas en ámbitos como la educación, la cultura, la promoción de la mujer, la vivienda, la sanidad y la protección del medio ambiente, lo que permite, por ejemplo, un reconocimiento de competencias en materia de igualdad de la mujer. Y competencias no mencionadas expresamente en la Ley de Bases, como las actividades cla- 
sificadas, pueden derivarse tanto de materias concretas a las que sí se refiere (medio ambiente, defensa de consumidores, etc.) como de la posibilidad que contempla su artículo 84 de intervenir la actividad de los ciudadanos mediante diversas técnicas, entre las que se encuentra el sometimiento a licencia y otros actos de control preventivo, característico de la actuación en materia de actividades clasificadas. Por último, en un análisis de detalle, puede apuntarse que en las competencias sobre ordenación del tráfico hay una falta de sintonía entre el artículo 25.2 de la Ley de Bases de Régimen Local y el artículo 20 de la Ley de Régimen Local de Castilla y León, ya que el primero se refiere a «Ordenación del tráfico de vehículos y personas en las vías urbanas», mientras que el segundo habla únicamente de «Ordenación del tráfico». Esta falta de coincidencia es menor.

Además de estas faltas de coincidencia, fácilmente explicables, llegamos a una conclusión de mayor importancia en la comparación de la normativa básica de régimen local, contenida en la Ley de Bases y en la legislación sectorial del Estado, que atribuye competencias a los municipios, y la legislación castellano-leonesa, que incluye la Ley de Régimen Local de Castilla y León y las normas reguladoras de los distintos sectores de acción administrativa que deberían atribuir alguna competencia a los municipios: el grado de reconocimiento de competencias a los municipios parece insuficiente en su realización castellano-leonesa con respecto al aparentemente pretendido por la legislación básica del Estado, por lo que parece que la reserva de ley del apartado tercero del artículo 25 de la Ley de Bases de Régimen Local no ha producido los resultados esperados en cuanto a la atribución de competencias a los municipios en las materias recogidas en el artículo 25 .

Esta primera conclusión requeriría para su plena confirmación un estudio más amplio para poder determinar si nos encontramos ante un balance exclusivo de esta Comunidad Autónoma o, en cambio, este resultado es extensible, al menos en parte, al resto de las Autonomías, lo que supondría un cierta frustración de las expectativas depositadas en la legislación sectorial de las Comunidades Autónomas por el artículo 2 de la Ley de Bases, y en suma denotaría reservas frente a la descentralización real. Caso de ser una situación peculiar de Castilla y León, en cambio, habría de preguntarse si se debe a la estructura municipal característica de esta Comunidad Autónoma, con un gran número de municipios pequeños que difícilmente serían capaces de asumir competencias en todos los sectores referidos en la Ley de Bases, por lo que ésta habría pecado de cierto desconocimiento de la realidad rural. 
A nuestro juicio, la particular realidad geográfica de Castilla y León, a la que se refiere la Exposición de Motivos de la Ley 1/1998 (dos millones y medio de habitantes distribuidos en 2.247 municipios, la mayoría de los cuales no llega ni a los 250 vecinos), condiciona en gran medida el reconocimiento de competencias a un gran número de municipios castellanos y leoneses, dada la insuficiencia de medios, no sólo de recursos financieros, sino de personal cualificado que pudiera responsabilizarse de la correcta ejecución de esas tareas. A esta circunstancia se refiere el artículo 2 de la Ley de Bases de Régimen Local, cuando habla de la «capacidad de gestión» como uno de los criterios de procedencia de la atribución de competencias. Y queda bien atendida en la Ley 1/1998, cuyo Título IX regula las relaciones entre la Comunidad Autónoma y los entes locales, dedicando sus dos primeros capítulos a las transferencias y delegaciones.

En este régimen, que invoca el mismo artículo 2 de la Ley de Bases de Régimen Local, se insiste en que transferencias y delegaciones sólo tendrán lugar cuando se garantice una más eficaz prestación de los servicios, o, en otros términos, cuando se mejore la eficacia de la gestión pública. Esta mejora de la eficacia está condicionada, como es natural, por la capacidad de gestión del ente local, razón por la que el artículo 84 de la Ley 1/1998 limita la transferencia y delegación de competencias a los municipios de población superior a 5.000 habitantes y a los mencionados en el artículo 79 de la Ley, que son aquellos «... que cuenten con servicios culturales, educativos, sanitarios, sociales, administrativos o de otra naturaleza mediante los cuales se satisfaga la demanda de los residentes en otros municipios limítrofes...», dignos a juicio del legislador autonómico, y de su ejecutora - la Junta-, de un tratamiento preferencial, también en lo que a la transferencia o delegación de competencias afecta. Eso sí, siempre que tengan capacidad de gestión, luego demuestren que son capaces de mejorar la eficacia en la prestación de los servicios (y de las competencias, por tanto) delegados o transferidos ${ }^{57}$.

Al comenzar la década de los noventa, Lorenzo MARTín-RETORTILLO apuntaba lo absurdo de una nueva centralización auspiciada desde las Comunidades Autónomas: «Resultaría muy soprendente $-\mathrm{y}$ sin base ni apoyo alguno- que en el intenso proceso de descentralización que ha experimentado el Estado, quienes desde los territorios han hecho gala de practicar el victimismo, apuntando a Madrid como centro de agravios,

\footnotetext{
${ }^{57}$ Reiteramos aquí nuestras reservas para con la figura contemplada en el artículo 79 de la Ley 1/1998, de Régimen Local de Castilla y León, ya que pensamos que puede ser utilizada como herramienta de clientelismo político, dada la ambigüedad del concepto jurídico indeterminado que utiliza y difícil control de la decisión de otorgar un «tratamiento preferencial».
} 
impidieran luego que la centralización corriera hacia abajo, hacia los escalones extremos, intentando bloquear en la altura regional lo que con toda naturalidad podría ser desempeñado por los municipios, intentando regatearles su legítimo protagonismo (allí donde los municipios tengan organización suficiente, insisto)» ${ }^{58}$.

El gran problema al que se enfrentan los municipios en Castilla y León no es el riesgo, ya suficientemente comprobado, de una nueva centralización, sino su fragilidad, al albur de lo que el legislador autonómico, y en algunos casos incluso el ejecutivo autonómico, quieran decidir. Citaría como ejemplo el artículo 95 del Decreto de la Junta de Castilla y León 266/1998, de 17 de diciembre, sobre sanidad animal, que bajo el rótulo «Obligaciones de los Ayuntamientos» establece que «Los Ayuntamientos deberán disponer del sistema adecuado para la destrucción de animales muertos o alternativamente de un terreno cerrado con las características expresadas en el apartado anterior». Y ello pese a que la Ley 6/1994, de 19 de mayo, de sanidad animal de Castilla y León, se limite a establecer en su artículo 26, sobre centros de tratamiento de cadáveres, que la Junta de Castilla y León fomentará el establecimiento y dotación de centros de tratamiento de cadáveres animales.

Continuando con el régimen jurídico de los animales, últimamente bien tratado ${ }^{59}$, puede citarse la Ley $5 / 1997$, de animales de compañía de Castilla y León, que atribuye competencias concretas a los municipios, pero prácticamente en términos de obligación, lo que supone cargarles con tareas a veces complejas y para las que pueden carecer de medios o recursos suficientes. Por ejemplo, llevar un censo municipal de animales de compañía (art. 9), habilitar zonas de esparcimiento y entrenamiento (art. 10), o recogida de los animales abandonados (art. 15). En fin, el resultado es que, en esta norma, como en tantas otras, la atribución de competencias a los municipios supone la realización de nuevas tareas, no la cesión de verdaderos espacios de poder, ni de mayores márgenes de decisión para abordar políticas propias.

\footnotetext{
58 Prólogo al libro de FAnLo Loras, Fundamentos constitucionales de la autonomía local, CEC, Madrid, 1990, p. 31.

59 Vid. Santiago Muñoz Machado y otros, Los animales y el Derecho, Civitas, Madrid, 1999.
} 


\section{CONCLUSIONES: ANTE EL FUTURO PACTO LOCAL EN CASTILLA Y LEÓN}

El somero análisis de la doctrina, la jurisprudencia y la legislación de régimen local demuestran, en sus proyecciones prácticas sobre la realidad municipal de Castilla y León, ciertas insuficiencias del modelo creado por la Ley de Bases de Régimen Local. Siendo una magnífica Ley, no ha conseguido alcanzar algunos de sus principales objetivos, como reconoce PAREJO Alfonso: «Tampoco ha conseguido la Ley, al menos por ahora, constituirse, en la práctica, en norma positivamente inspiradora de la legislación sectorial» ${ }^{60}$. Y el relativo fracaso de la Ley de Bases de Régimen Local se puede deber, probablemente, al papel decisivo que corresponde a cada Comunidad Autónoma en la ejecución de una verdadera política local de racionalización y descentralización. SOSA WAGNER lo ha explicado con claridad meridiana: «los instrumentos puestos en manos de las Comunidades Autónomas para realizar una política firme que condujese a una nueva dimensión de los municipios apenas si han sido utilizados, quedando así defraudadas las viejas aspiraciones de la descentralización política y administrativa que tenía, en esta materia, un buen campo donde poner en pie una experiencia inédita en nuestra historia que, en manos del Estado, había resultado fallida» ${ }^{61}$.

En Castilla y León esta política se plantea ahora, para evitar que poco a poco los municipios pierdan competencias o sean incapaces de ejercitarlas, subrogándose la Comunidad Autónoma en su ejercicio, hasta que la despoblación del territorio acabe con cientos de municipios protegidos firmemente por la «garantía institucional». Sólo el fortalecimiento de los municipios mediante la creación de figuras asociativas más sólidas y ambiciosas que las mancomunidades, y una decidida intervención sobre el mapa municipal puede, a nuestro juicio, coadyuvar a que en Castilla y León recupere su pulso la autonomía local. El relevo en la Consejería de Presidencia y Administración Territorial ha supuesto, en este sentido, un impulso decidido a la política local, con el anuncio de un próximo Pacto que negocian Junta y Ayuntamientos. Se pretende que este compromiso se formalice, tras sucesivas fases, antes de 2003. Entre las competencias municipales que podrían contemplarse podemos mencionar educación, deporte, cultura, juventud, asuntos sociales, mujer, salud, consumo, me-

\footnotetext{
${ }^{60}$ Parejo Alfonso, «El régimen jurídico de la Administración local, hoy», en La posición institucional de la Administración local ante el siglo XXI, cit., p. 39.

${ }^{61}$ Francisco SoSA WAGNeR, «Creación y supresión de municipios y alteraciones de sus términos», en La posición institucional de la Administración local ante el siglo XXI, cit., p. 107.
} 
dio ambiente, empleo, industria o turismo. El Pacto Local en Castilla y León supondrá un incremento de las competencias municipales, y por tanto una mayor realización de la autonomía local y del principio de subsidiariedad en esta Comunidad Autónoma. 
REAL-2001, núm. 286-287. RIVERO ORTEGA, RICARDO. AUTONOMÍA LOCAL Y COMPETENCIAS:...

REAL-2001, núm. 286-287. RIVERO ORTEGA, RICARDO. AUTONOMÍA LOCAL Y COMPETENCIAS:... 